\title{
Characterization of Mechanical Properties of Jute/PLA Composites Containing Nano SiO2 Modified By Coupling Agents
}

\section{Xueyang Song}

Soochow University

\section{Cuicui Fang}

Soochow University

\section{Yuanyuan Li}

Soochow University

Ping Wang ( $\square$ pingwang@suda.edu.cn )

Soochow University https://orcid.org/0000-0001-6692-3850

\section{Yan Zhang}

Soochow University

\section{Research Article}

Keywords: laminating composite materials, Jute non-woven, PLA, biodegradable, nano-SiO2

Posted Date: September 20th, 2021

DOI: https://doi.org/10.21203/rs.3.rs-870428/v1

License: (a) (i) This work is licensed under a Creative Commons Attribution 4.0 International License. Read Full License

Version of Record: A version of this preprint was published at Cellulose on November 23rd, 2021. See the published version at https://doi.org/10.1007/s10570-021-04300-z. 
Characterization of mechanical properties of jute/PLA composites containing nano $\mathrm{SiO}_{2}$ modified by coupling agents

\author{
Xueyang Song, Cuicui Fang, Yuanyuan Li, Ping Wang, Yan Zhang* \\ National Engineering Laboratory for Modern Silk, College of Textile and Clothing \\ Engineering, Soochow University, Suzhou, China \\ * Corresponding author: Yan Zhang (yanzhng86@suda.edu.cn)
}

\begin{abstract}
Although jute fibers-reinforced PLA composites shows strong application prospects, their low mechanical properties limit their applications to some extent. In this paper, nano- $\mathrm{SiO}_{2}$ particles as well as modified nano $\mathrm{SiO}_{2}$ by coupling agents which can efficiently improve the strength and toughness of composite materials are introduced into the PLA matrix. The bending, stretching and thermal properties of designed jute/PLA nonwoven composites were studied. The study shows that the nano- $\mathrm{SiO}_{2}$ particles are beneficial to the interface performance between the PLA matrix and jute leading to improvement in the mechanical property and thermal stability. Moreover, thermomechanical properties indicate that the addition of $\mathrm{SiO}_{2}$ can improve the jute/PLA interfacial adhesion and increase the glass transition temperature of the material. Finally, toughening mechanism of nano- $\mathrm{SiO}_{2}$ particles in the jute/PLA composite was analyzed.
\end{abstract}

Keywords: laminating composite materials; Jute non-woven; PLA; biodegradable; nano- $\mathrm{SiO}_{2}$ 


\section{Introduction}

In recent years, thermoplastic composites are increasingly applied in the high-performance engineering field due to their low density, good recyclability, and high production efficiency (Faruk et al. 2012). However, environmental compatibility of these materials is still a huge challenge. In this case, fully biodegradable green composite materials provide a feasible solution. To prepare a completely biodegradable composite material, natural fiber is a desirable reinforcing material and natural polymer can be selected as matrix material, such as jute/polylactic acid (PLA) composite materials. PLA, a polymer material, is produced from renewable agricultural raw materials. It has tremendous advantages such as high strength, high hardness, transparency and industrial production, and is one of the most promising biodegradable polymers (Qu et al. 2015). Among all biodegradable reinforced fibers, jute fiber has low cost, biodegradability and excellent mechanical property, which has made it as one of the most widely used natural plant fibers in the research of green bio-based composites (Dong et al. 2014). There are wide possible applications for jute/PLA composite, and a lot of research have been proposed to investigate its mechanical properties (Bax and Mussig 2008; Mohammed et al. 2019; Nishino et al. 2003; Pan et al. 2007). However, PLA resin matrix lacks chemical bonds and functional groups that react with jute. Therefore, the interface compatibility between jute fiber and PLA is poor, leading to a poor mechanical property of final composite. (Balla et al. 2019; Costa et al. 2012; He et al. 2019; Hossen et al. 2020; Pereira et al. 2019). At present, some physical and chemical methods have been proposed, including fiber treatment technologies such as acylation, alkali treatment, etherification and isocyanate treatment, as well as the use of coupling agents to improve the interfacial bonding properties of jute/PLA composites (Dong et al. 2020; Fang et al. 2020; Huda et al. 2007; Kumar et al. 2010; Kakroodi et al. 2012). Nano particle is also a feasible option to toughen the polymer matrix and improve the mechanical properties of fiber-reinforced composites.

In recent years, nano particles have been extensively applied to prepared composites, which has significantly improved the mechanical properties of 
composites materials (Gauvin et al. 2015; Jumahat et al. 2012; Jumahat et al. 2010). Among the nanoparticles used as reinforcing materials, many researchers chose doping nano-silica (nano- $\mathrm{SiO}_{2}$ ) to improve the mechanical properties of fiber-reinforced composite materials (Jumahat et al. 2015; Jumahat et al. 2012; Jumahat et al. 2010). Luo et al. (2018) used technology-resin film infusion (RFI) technology to prepare nano- $\mathrm{SiO}_{2}$ modified carbon fiber reinforced composite materials. When the content of nano- $\mathrm{SiO}_{2}$ is $4 \mathrm{wt} \%$, the toughening and strengthening effect is the best. The tensile strength and flexural strength increased to 595.69 and 703.76 MPa, respectively, which were $86.30 \%$ and $126.98 \%$ higher than the tensile strength and flexural strength of intact sample without $\mathrm{SiO}_{2}$. Hashim et al. (2019) studied the effect of $\mathrm{SiO}_{2}$ nanoparticles as a reinforcing filler on the tensile response of basalt fiber reinforced polymer (BFRP) composites. It was found that the addition of $\mathrm{SiO}_{2}$ nanoparticles showed significant improvement in tensile modulus with $6 \%$, $14 \%$ and $19 \%$ for $5 \mathrm{wt} \%, 15 \mathrm{wt} \%$ and $25 \mathrm{wt} \%$ nano-SiO${ }_{2}$ content, respectively. Reddy et al. (2010) used traditional melt blending technology to prepare low nanoparticle loaded polymer composites with improved mechanical properties. The results of tensile tests indicate that the addition of $\mathrm{SiO}_{2}$-g-DGEBA particles to the polymer matrix led to an increase of both elastic modulus and toughness (from 0.36 to 0.54 $\mathrm{GPa}$, and 19.06 to $21.05 \mathrm{MJ} / \mathrm{m}^{3}$, respectively). Filling nano-SiO 2 into thermoplastic matrix can combine the rigidity of nano- $\mathrm{SiO}_{2}$ with the toughness of thermoplastic matrix, which makes ultimate composite have comprehensive mechanical performance (Hashim et al. 2019; Luo et al. 2018; Park et al. 2020).

In this study, nano-SiO 2 particles were adopted and dispersed into the PLA matrix aiming to improve the mechanical property of jute/PLA composite. Moreover, considering the dispersibility, the nano- $\mathrm{SiO}_{2}$ was first modified with different silane coupling agents, then combined into PLA-based composite films and finally incorporated in final laminated composites. This use of sandwich-like lamination structure layer can mix PLA and jute as evenly as possible. Therefore, the effect of silane coupling agents on the mechanical property of as-prepared composites via hot-pressing technology was comprehensively analyzed. 


\section{Materials and methods}

\section{Materials}

PLA (4032D; $\left.1.24 \mathrm{~g} / \mathrm{cm}^{3}\right)$ was supplied by Nature Works, USA; Jute fibers (1.45 $\left.\mathrm{g} / \mathrm{cm}^{3}\right)$ was purchased from Shandong Jiangke Linyi Co., Ltd; Nano silica $\left(\mathrm{SiO}_{2}\right.$, 99.5\%, 50 $\pm 5 \mathrm{~nm}$ ) was provided by Suzhou Great Medical Technology Co., Ltd; Silane coupling agent (KH550, KH560, KH570) chemicals were provided by Jiangsu Argon Krypton Xenon Material Technology Co., Ltd. KH550 $\left(\mathrm{NH}_{2} \mathrm{CH}_{2} \mathrm{CH}_{2} \mathrm{CH}_{2} \mathrm{Si}\left(\mathrm{OC}_{2} \mathrm{H}_{5}\right)_{3}\right)$ belongs to aminosilane, KH560 $\left(\mathrm{CH}_{2} \mathrm{OCHCH}_{2} \mathrm{O}\left(\mathrm{CH}_{2}\right)_{3} \mathrm{Si}\left(\mathrm{OCH}_{3}\right)_{3}\right)$ belongs to epoxy silane, $\mathrm{KH} 570$ $\left(\mathrm{CH}_{3} \mathrm{CCH}_{2} \mathrm{COO}\left(\mathrm{CH}_{2}\right)_{3} \mathrm{Si}\left(\mathrm{OCH}_{3}\right)_{3}\right)$ belongs to formaldehyde acryloyloxy functional group silane.

\section{Preparation of modified $\mathrm{SiO}_{2}$}

The absolute ethyl alcohol and deionized water were first mixed with a mass ratio of 9:1, and $5 \mathrm{~g}$ of $\mathrm{SiO}_{2}$ was added into $100 \mathrm{~mL}$ of mixture. The $\mathrm{SiO}_{2}$ solution was then sonicated in an ultrasonic cleaner for $1 \mathrm{~h}$. The coupling agent, e.g. KH550, with a volume of $5 \%$ of the mixture was prepared and adjusted to the $\mathrm{pH}$ of 4 with oxalic acid. The above mixed solutions were magnetically stirred for $3 \mathrm{~h}$ at $60{ }^{\circ} \mathrm{C}$ for reaction. Finally, it was centrifuged (model: TG16G) and then washed with absolute ethanol solution for 3 times. The obtained precipitate was dried in an oven at $60{ }^{\circ} \mathrm{C}$ for $4 \mathrm{~h}$ to obtain modified $\mathrm{SiO}_{2}$ powders, named as $\mathrm{KH} 550-\mathrm{SiO}_{2}, \mathrm{KH} 560-\mathrm{SiO}_{2}$ and $\mathrm{KH} 570-\mathrm{SiO}_{2}$ respectively. The scheme of preparation process of modified $\mathrm{SiO}_{2}$ is illustrated in Figure 1. 


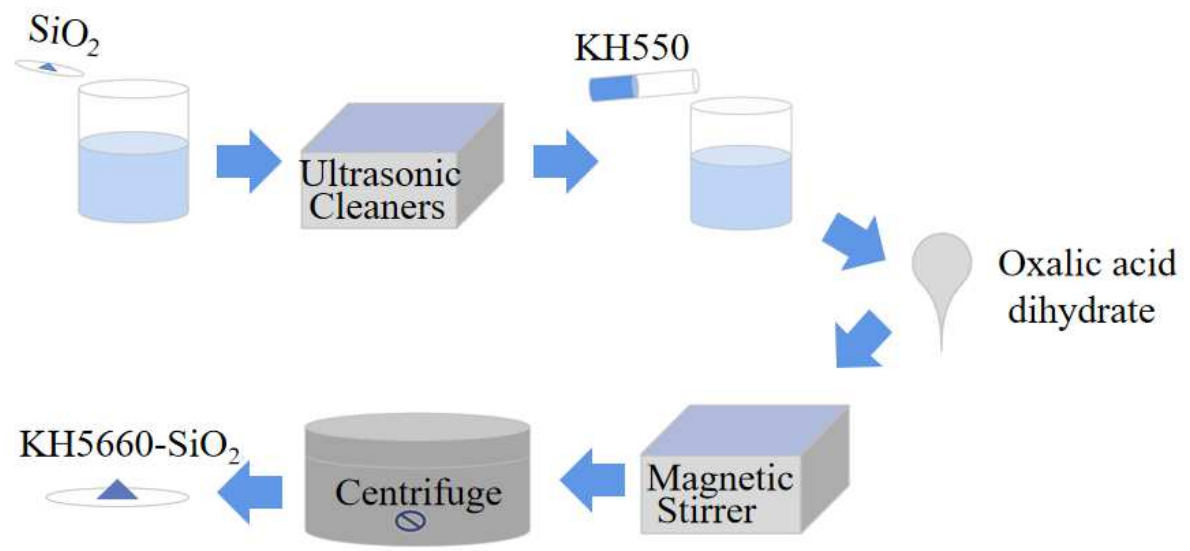

108

109

110

111

112

113

114

115

116

117

118

119

120

121

122

123

124

125

126

Fig. 1 The scheme of preparation process of modified $\mathrm{SiO}_{2}$

\section{Preparation of composite $\mathrm{SiO}_{2}-\mathrm{PLA}$ films}

$3 \mathrm{~g}$ of PLA raw material was dissolved it in dichloromethane, stirred magnetically (model: DF-101S) for $1.5 \mathrm{~h}$ at room temperature; different mass fractions of modified $\mathrm{SiO}_{2}(0.5 \mathrm{wt} \%, 1 \mathrm{wt} \%, 2 \mathrm{wt} \%, 4 \mathrm{wt} \%$ and $8 \mathrm{wt} \%)$ were mixed into dichloromethane and ultrasonicated (model: VGT-1730QT) for $40 \mathrm{~min}$. These two solutions were mixed and magnetically stirred for $2 \mathrm{~h}$, followed by ultrasonication for $1 \mathrm{~h}$ at $35{ }^{\circ} \mathrm{C}$. Then, the solution was poured into a glass plate and placed in a fume hood at room temperature to make the methylene chloride solvent completely volatilize. Finally, the composite $\mathrm{SiO}_{2}$-PLA film was peeled from the mold and placed in a vacuum oven at a temperature of $45^{\circ} \mathrm{C}$ for $3 \mathrm{~h}$, as shown in Figure 2.

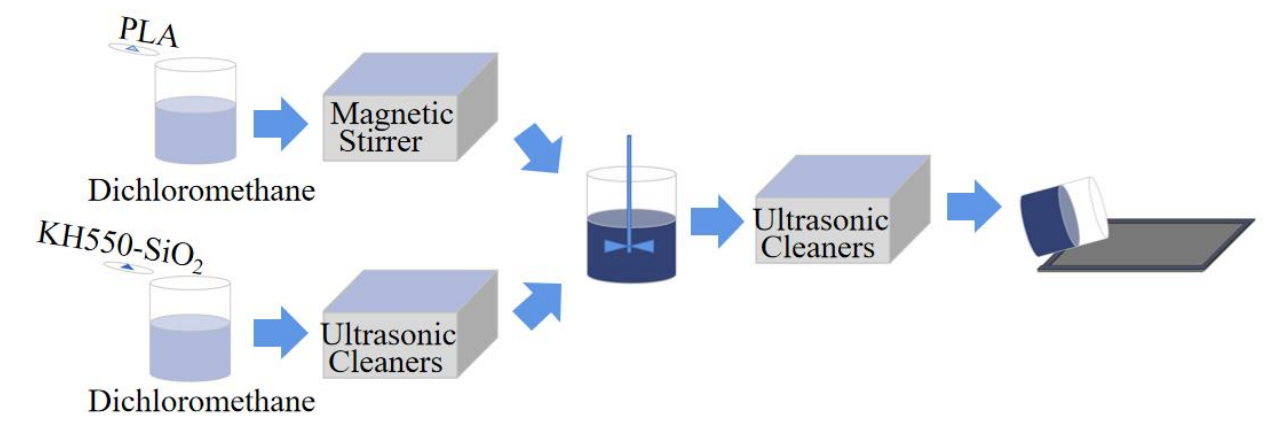

Fig. 2 The scheme of preparation process of composite $\mathrm{SiO}_{2}-\mathrm{PLA}$ film

Preparation of jute non-woven

The preparation process of jute non-woven is shown in Figure 3. The aspect ratio 
of jute fiber is about 314:1. First, the fluffy jute fibers was combed, opened and mixed through a coarse-garge carding machine (model: SSL-II) to make the fibers looser and more uniform. Then the loose jute fibers were sent to the blender for further fine opening. The fine opening and carding process make the jute fibers finally become a fluffy and uniform fiber web. The fiber web obtained by cross-netting has higher quality. In order to obtain a certain strength of non-woven fabrics, the four-layer jute net were finally reinforced with a needle punch (model: CSZC). The final thickness of the jute nonwoven is $0.51 \pm 0.04 \mathrm{~mm}$, and the surface density is $200 \pm 2 \mathrm{~g} / \mathrm{m}^{2}$.

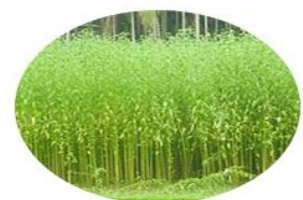

Plant

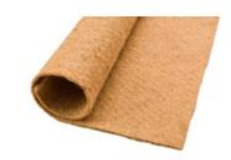

Jute nonwovens

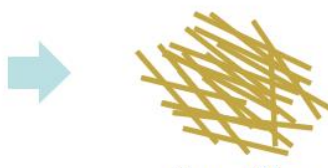

Jute fiber

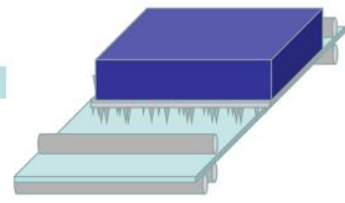

Pre-needling

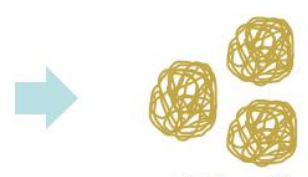

Blending

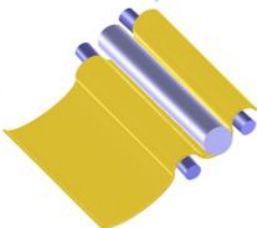

Cross lapping

Fig. 3 The preparation process of jute non-woven fabric

\section{Preparation of composite material}

To remove all moisture, $\mathrm{SiO}_{2}$-PLA films and jute nonwoven were first dried in a vacuum oven at $80{ }^{\circ} \mathrm{C}$ for $6 \mathrm{~h}$ before hot pressing. The laminated composite material was processed through a compression mold using a film stacking method, in which two jute pads were arranged between three PLA films in parallel, as demonstrated in Figure 4. The entire assembly was then placed in a steel mold controlled under different time and temperature. The laminated material is compacted for $0.5 \mathrm{~h}$ under the conditions of a temperature of $180{ }^{\circ} \mathrm{C}$ and a pressure of $1 \mathrm{MPa}$, and then is naturally cooled in the vulcanization machine(model: HG-3621) for $8 \mathrm{~h}$. After $8 \mathrm{~h}$, the sample was taken out of the laminating mold, and the width and length were $150 \mathrm{~mm}$ $\times 150 \mathrm{~mm}$ and the thickness was $2 \mathrm{~mm}$, and the mass ratio of PLA to jute was 10:3. 
149 The samples are numbered according to the type of coupling agent and concentration.

150 For example, 550-0.5, in which 550 represents the silane coupling agent of KH550,

151 the sample untreated with the coupling agent is directly represented by $\mathrm{SiO}_{2}$, and 0.5

152 represents $0.5 \mathrm{wt} \%$ of the modified $\mathrm{SiO}_{2}$ mass fraction in $\mathrm{SiO}_{2}-\mathrm{PLA}$ film.

153

154

155

156

157

158

159

160

161

162

163

164

165

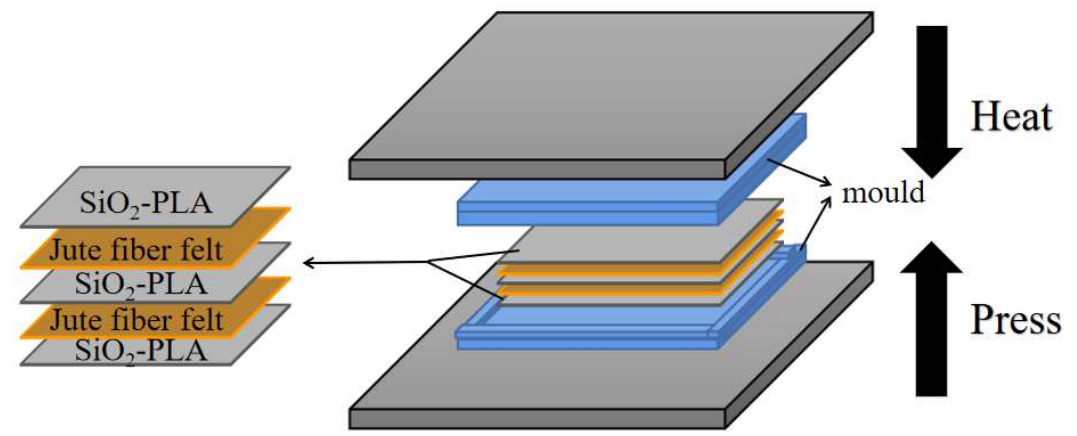

Fig. 1 The preparation process of composite material

\section{Characterization of jute / PLA composites}

In order to study that effect of different silicon dioxide on the mechanical properties of jute/PLA composite, the $\mathrm{SiO}_{2}$ modified by silane coupling agent was characterized by infrared transmission spectroscopy (5700, Nicli Instruments, USA) and particle size analyzer (LS-909). At the same time, the mechanics of composite materials were characterized by scanning electron microscope (TM3030, Hitachi, Japan), dynamic mechanical thermal analysis (SDTQ800, V21.3, Build 96, USA) and related mechanical testing methods (Instron 336, USA).

\section{Results and discussions}



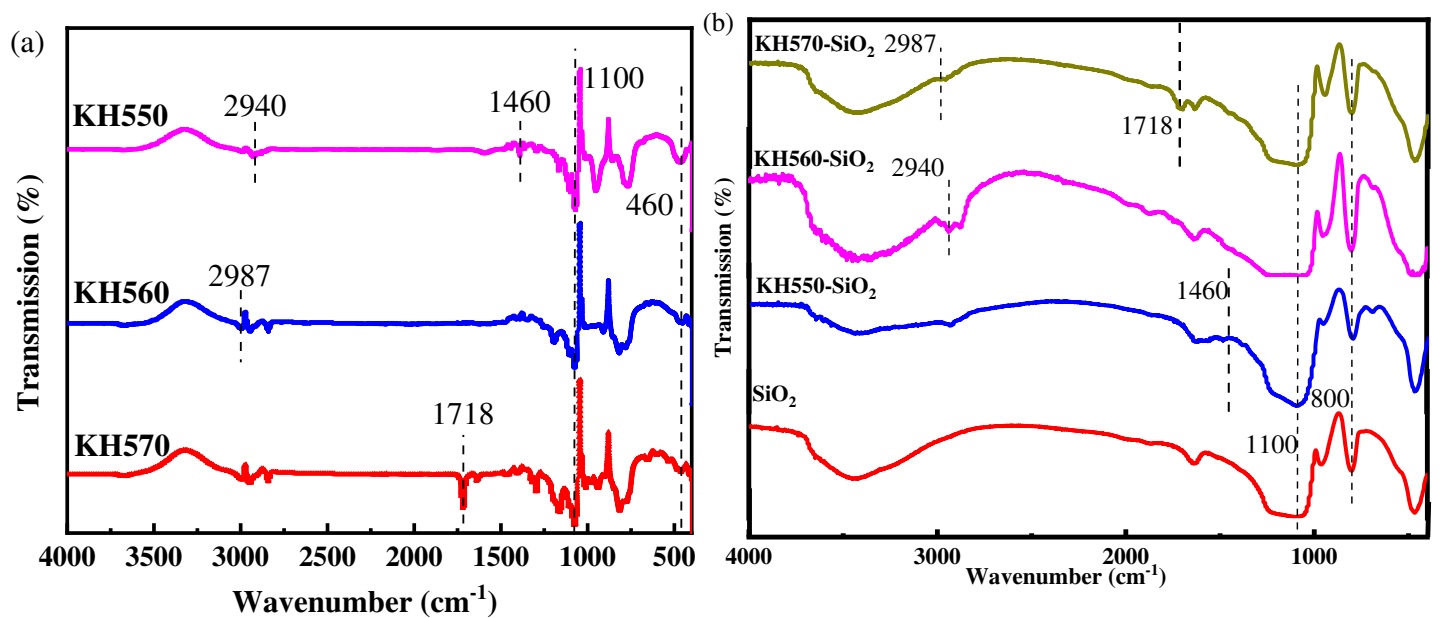

Fig. 5 (a) FTIR spectra of KH550, KH560 and KH570; (b) FTIR spectra of $\mathrm{SiO}_{2}$, $\mathrm{KH} 550-\mathrm{SiO}_{2}, \mathrm{KH} 560-\mathrm{SiO}_{2}$ and $\mathrm{KH} 570-\mathrm{SiO}_{2}$ nanoparticle

Fourier-transform infrared spectroscopy (FTIR) can be used to verify the graft polymerization of silane coupling agents on SBR surface. Figure 5 shows the infrared spectra of KH550, KH560 and KH570 as well as corresponding silane coupling agent grafted $\mathrm{SiO}_{2}$. It can be seen from Figure 5 (b) that the infrared spectrum of the $\mathrm{SiO}_{2}$ before and after modification has a large absorption peak near $1100 \mathrm{~cm}^{-1}$, which is the antisymmetric absorption peak of Si-O-Si bond, and near $800 \mathrm{~cm}^{-1}$ is the symmetrical contraction vibration of the $\mathrm{Si}-\mathrm{O}-\mathrm{Si}$ bond. The infrared spectrum of $\mathrm{KH} 550-\mathrm{SiO}_{2}$ is relatively flat compared to others in the range of $3500-3100 \mathrm{~cm}^{-1}$, indicating that $-\mathrm{NH}_{2}$ in KH550 has been successfully grafted and modified on the surface of nano-SiO 2 . In Figure 5 (a), KH550 shows characteristic peaks of $-\mathrm{CH}_{2}$ - at $2940 \mathrm{~cm}^{-1}$ and $1640 \mathrm{~cm}^{-1}$, while $\mathrm{KH} 550-\mathrm{SiO}_{2}$ also has a shoulder peak at $2940 \mathrm{~cm}^{-1}$ and $1460 \mathrm{~cm}^{-1}$, which further indicates that $\mathrm{KH} 550$ has successfully modified nano-SiO 2 . Compared with FTIR spectrum of $\mathrm{SiO}_{2}$, in the spectrum modified by $\mathrm{KH} 560-\mathrm{SiO}_{2}$, the stretching vibration absorption peak of methyl appears near $2987 \mathrm{~cm}^{-1}$ which is related to characteristic methyl peak of KH560, indicating that KH560 silane coupling agent has been successfully grafted to the second Si-O surface (He et al. 2019). In the infrared spectrum of $\mathrm{KH} 570$ and $\mathrm{KH} 570-\mathrm{SiO}_{2}$, there is a $\mathrm{C}=\mathrm{O}$ stretching vibration absorption 
peak on the carbonyl group at $1718 \mathrm{~cm}^{-1}$, which indicates that KH570 has been successfully grafted onto nano- $\mathrm{SiO}_{2}$.

The particle size of original and modified $\mathrm{SiO}_{2}$ is shown in Table 1. The surface

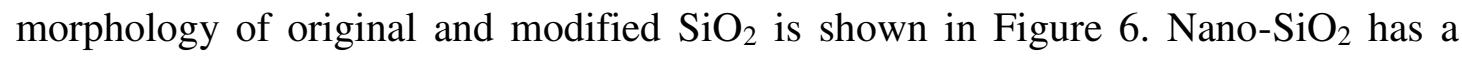
small particle size, a large specific surface area. Due to the large specific surface area, the powder is easy to agglomerate together, so that the total surface area is reduced, and the total energy is reduced. It can be clearly seen that the unmodified particles are larger than modified particles, and $\mathrm{KH} 560$ has the best modification effect on $\mathrm{SiO}_{2}$ particles. Unmodified nano- $\mathrm{SiO}_{2}$ has a relatively high polydispersity index (PDI) and the particle size, particle size, and unevenness appeared and severe aggregation. The particle size and PDI of the modified nano- $\mathrm{SiO}_{2}$ powder are reduced, indicating that the nano- $\mathrm{SiO}_{2}$ modified by the silane coupling agent can effectively prevent its agglomeration and achieve the modification purpose. On the one hand, the hydroxyl groups on the particle surfaces are replaced by organic functional groups, reducing the number of active silanol groups, thereby reducing the tendency of nanoparticles to agglomerate. On the other hand, the grafted long carbon chain increases the distance between particles and the steric hindrance of the hydroxysilyl polycondensation reaction on the particle surface, which increases the difficulty of effective collisions and more conducive to the dispersion of nanoparticles.

Table 1 The spectification of prepared nano $\mathrm{SiO}_{2}$

\begin{tabular}{ccccc}
\hline Sample & $\begin{array}{c}\text { Z-Average } \\
(\mathrm{nm})\end{array}$ & $\begin{array}{c}\text { Peak Size } \\
(\mathrm{nm})\end{array}$ & $\begin{array}{c}\text { Peak Intensity } \\
(\%)\end{array}$ & PDI \\
\hline $\begin{array}{c}\mathrm{SiO} \\
\mathrm{KH} 550-\mathrm{SiO}_{2}\end{array}$ & 300 & 220.8 & 65.2 & 0.343 \\
$\mathrm{KH} 560-\mathrm{SiO}_{2}$ & 67.6 & 143.3 & 69.3 & 0.287 \\
$\mathrm{KH} 570-\mathrm{SiO}_{2}$ & 91 & 92.7 & 100 & 0.210 \\
\hline
\end{tabular}




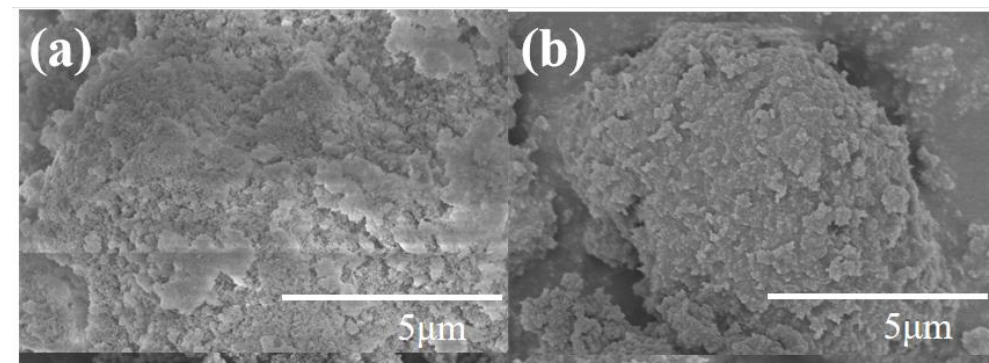

Fig. 6 The surface morphology of $\mathrm{SiO}_{2}$. (a) $\mathrm{SiO}_{2}$; (b) $\mathrm{SiO}_{2}-550$; (c) $\mathrm{SiO}_{2}-560$; (d) $\mathrm{SiO}_{2}-570$

\section{Bending property}
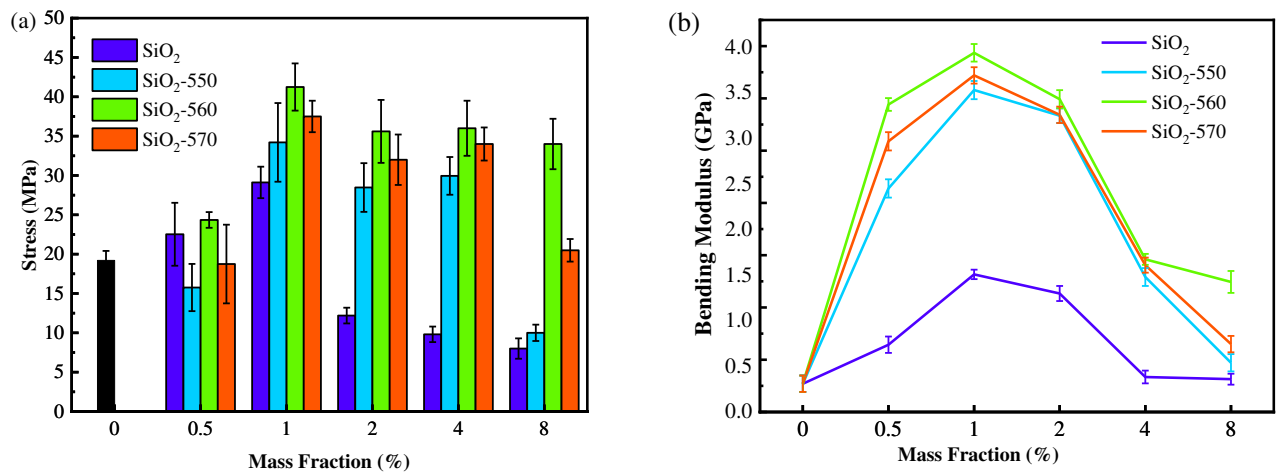

(c)

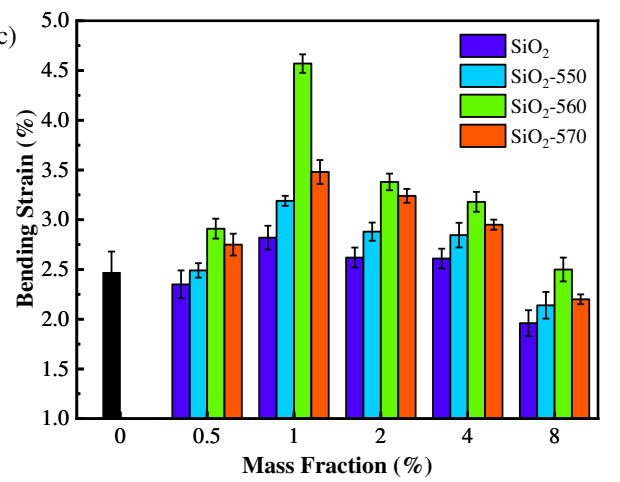

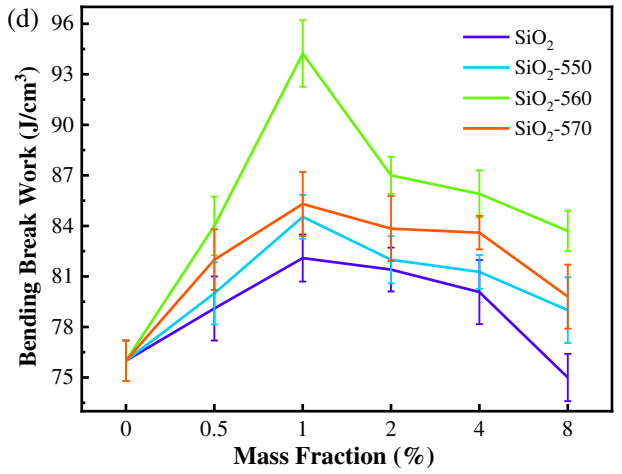

Fig. 7 The effect of nano- $\mathrm{SiO}_{2}$ on tensile properties of jute/PLA composite bending 
The experiment was repeated at least 5 times for each sample. Figure 7 (a) and (b) shows the bending strength and modulus of pure jute/PLA fibers composites involving $\mathrm{SiO}_{2}$ and modified $\mathrm{SiO}_{2}$ nanoparticles with different mass fractions. It can be seen that the bending modulus of jute/PLA fibers composites is relatively low. With incorporation of $\mathrm{SiO}_{2}$, the bending strength and modulus of the composites is more or less improved. Compared with pure jute/PLA composite material, there is no significant improvement in the bending performance of the sample $\mathrm{SiO}_{2}-4$. However, after adding the nano- $\mathrm{SiO}_{2}$ particles modified by the coupling agents, the bending strength and modulus of 550-4 increased to $29.95 \mathrm{MPa}$ and 1.25 GPa respectively, which were $149.5 \%$ and $76.8 \%$ higher than those of the jute/PLA composite, and increased by $137.4 \%$ and $72.0 \%$ compared with the unmodified $\mathrm{SiO}_{2}$ jute/PLA composite. The bending strength and modulus of 560-4 were increased to $36 \mathrm{MPa}$ and 2.17 GPa respectively, and the bending strength and modulus of 570-4 were $34 \mathrm{MPa}$ and 2.01 GPa. Compared with the jute/PLA fibers composites, the bending strength of 560-0.5, 560-1, 560-2, 560-4 and 560-8 composites increased by $2.8 \%, 96.6 \%, 74.7 \%$, $74.2 \%$ and $68.3 \%$ respectively. It is also found from Figure 7 (a) and (b) that as the mass fraction of different types of added $\mathrm{SiO}_{2}$ increases, the change trend of material bending strength and modulus is basically same.

The similar phenomena can be also observed in the bending strain and bending break work of jute/PLA composites. The bending break work was calculated by integrating the tensile stress-strain curves. As shown in Figure 7 (b), the increase of $\mathrm{SiO}_{2}$ improves the bending strain and bending break work of jute/PLA composites.

In short, the bending performance of the sample increases with the increase of the $\mathrm{SiO}_{2}$ mass fraction, peaks at about $1 \mathrm{wt} \%$, and then decreases. That is, under the same mass fraction, $\mathrm{SiO}_{2}$ treated with different silane coupling agents has the same effect on the jute/PLA composite. The $\mathrm{SiO}_{2}$ sample modified with $\mathrm{KH} 560$ has the best bending strength and modulus. It is mainly due to the fact that realize the interface combination through the coupling agent, forming a better entirety, and then strengthening the effect of stress transmission(Yang et al. 2009; Sanivada et al. 2020; Fang et al. 2020; Li et al. 2013). Sample 560-1 has best bending performance 
resulting from the excellent dispersibility and uniform particle size as illustrated in Table 1.

\section{The fracture morphology}

In order to illustrate the toughening mechanism, the fracture morphology of the reinforced PLA-based composite after the tensile test is shown in Figure 8. The tensile fracture surface of the jute/PLA composite, illustrated in Figure 8 (a), shows large amounts of fiber extraction leading to a lower mechanical resistance to some extent. This is consistent with comparatively large elongation ratio of the composite material which also indicates a poor interfacial cohesiveness. Figure 8 (b) shows the $\mathrm{SiO}_{2}$ particles modified by KH560 are evenly distributed in PLA matrix. At this time, delamination occurs in the tensile section, and the bending strength is reduced. With the increase of $\mathrm{SiO}_{2}$, there are more holes appeared which are prone to cause fracture. Nano- $\mathrm{SiO}_{2}$ particles induce local plastic deformation of the PLA matrix, showing a rougher fracture surface. And as the stress concentration point, $\mathrm{SiO}_{2}$ particles produce a large number of small cracks, and has a small amount of fibers extraction, as shown in the Figure 8 (d). There are a large number of cracks and fiber extraction at the break of sample 560-4. Therefore, sample 560-4 consumes a lot of energy when it breaks. Due to the poor dispersibility of $\mathrm{SiO}_{2}$, the modified $\mathrm{SiO}_{2}$ re-aggregated at $8 \%$ by mass fraction. As the mass fraction of $\mathrm{SiO}_{2}$ increases, there are more contact points between $\mathrm{SiO}_{2}$ and jute, which reduces the adhesion between jute and PLA, and the mechanical properties dropped rapidly, as shown in Figure 8 (f). 


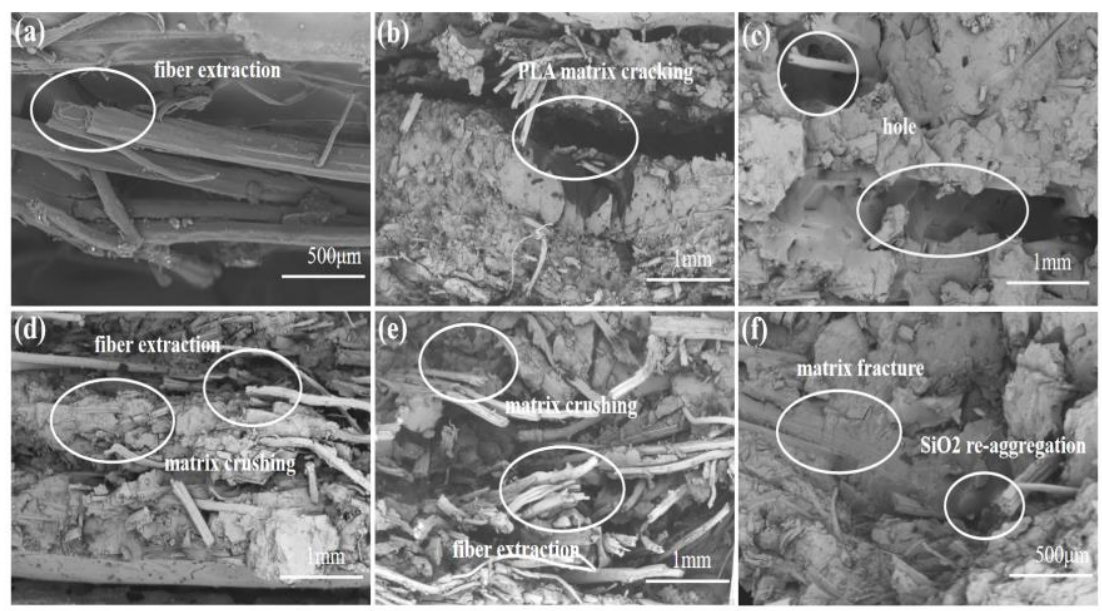

Fig. 8 The fracture surface morphologies of jute/PLA composite $(\times 200)$. (a) jute/PLA
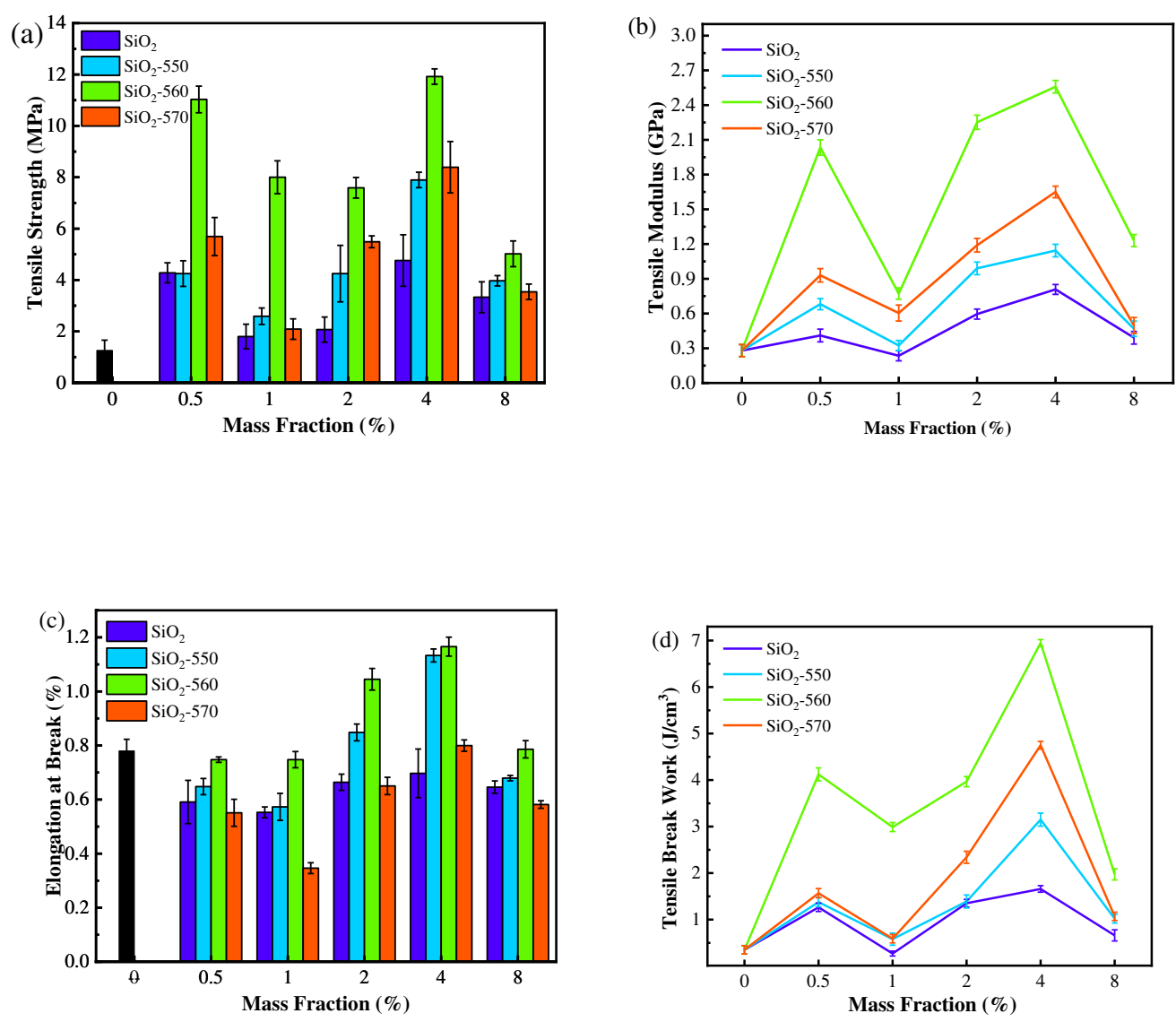
Fig. 9 The effect of nano-SiO 2 on tensile properties of jute/PLA fibers composites. (a) Tensile strength; (b)modulus; (c) Elongation at break; (d) Tensile break work

The tensile property of the jute/PLA composite and the nano-SiO $\mathrm{S}_{2}$ jute/PLA composites is shown in Figure 9. The tensile strength of 560-0.5 increased from 1.47 $\mathrm{MPa}$ in the jute/PLA composites to $11.03 \mathrm{MPa}$. The elastic modulus of 560-0.5 is as high as $2.01 \mathrm{GPa}$, which is $614.2 \%$ higher than the $0.28 \mathrm{GPa}$ of the jute/PLA composites. The tensile strength of 560-1 is $8 \mathrm{MPa}$ and the elastic modulus of 560-1 is $0.81 \mathrm{GPa}$. The tensile strength of $560-2$ is $7.59 \mathrm{MPa}$ and the elastic modulus is 2.32 $\mathrm{GPa}$. The tensile strength of $560-4$ is $11.92 \mathrm{MPa}$ and the elastic modulus is $2.57 \mathrm{GPa}$. The tensile strength of $560-8$ is $5.02 \mathrm{MPa}$ and the elastic modulus is $1.20 \mathrm{GPa}$. The tensile break work of $\mathrm{SiO}_{2}-4,550-4,560-4$, and 570-4 is increased by $138.0 \%$, $389.7 \%, 609.5 \%, 417.0 \%$ compared with the jute/PLA fibers composites.

It is concluded from Figure 9 that the cooperation of nano- $\mathrm{SiO}_{2}$ can effectively improve the tensile tolerance of composite materials. With the increase of nano- $\mathrm{SiO}_{2}$ content, the change trend of the tensile properties of the composite material before and after modification is basically the same. And when the $\mathrm{SiO}_{2}$ mass fraction is same, the sample modified by KH560 has the best tensile strength. This can be attributed to the small particle size and uniform shape of $\mathrm{SiO}_{2}$ modified by $\mathrm{KH} 560$, which is consistent with the DLS data.

When preparing jute/PLA laminates, $\mathrm{SiO}_{2}$ can be more evenly dispersed in the matrix, thereby enhancing the effective load transfer between jute and PLA, improving the tensile properties of the composite material. The silane coupling agent can serve as a bridge to improve the compatibility of the interface between $\mathrm{SiO}_{2}$ and jute/PLA, forming a better whole, and then strengthening the stress transmission. Figure 10 shows the interaction between the silica particles and the interface of the jute/PLA composite before and after the modification. The silane coupling agent can react with the silicon hydroxyl group on the surface of $\mathrm{SiO}_{2}$ after being hydrolyzed. The degree of aggregation of modified- $\mathrm{SiO}_{2}$ is reduced, exposing more binding sites that can interact with PLA. At the same time, the long-chain structure of the coupling 
agent will generate entanglement on the interface between jute fiber and PLA, which efficiently enhances the interface bonding performance, expedites interfacial stress transfer, and ultimately improves the mechanical property of the composite material.

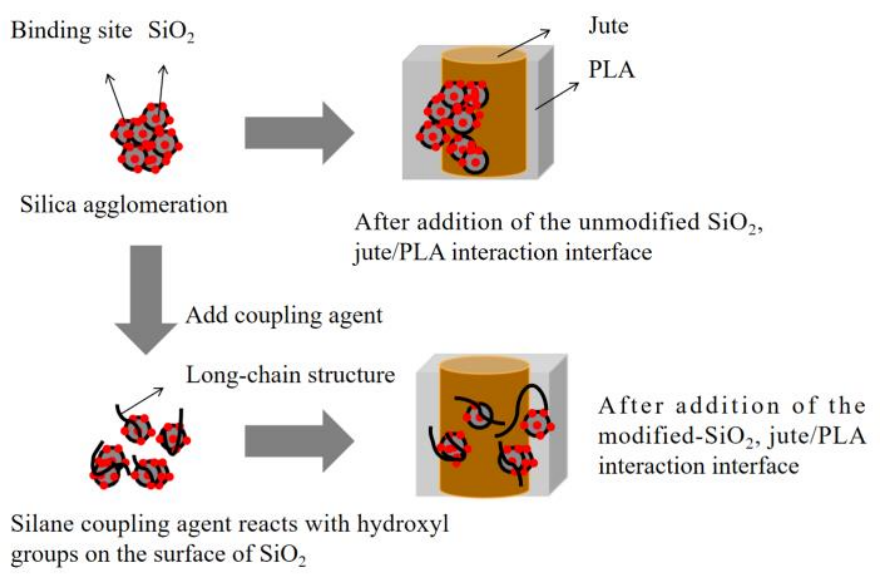

Fig. 10 The interaction between the silica particles and the interface of the jute/PLA composite before and after the modification of the silane coupling agent.

\section{Dynamic mechanical thermal analysis (DMTA)}

Figure 11 respectively show the dynamic storage modulus (E'), loss modulus (E") and loss coefficient tan $\delta\left(\mathrm{E}^{\prime \prime} / \mathrm{E}^{\prime}\right)$ of jute/PLA composites with different contents of $\mathrm{SiO}_{2}$ modified from room temperature to $180^{\circ} \mathrm{C}$. As shown in Figure 11 (a) and (b), the stored modulus values and corresponding temperatures of different samples at the beginning of chain segment movement. In the temperature range studied, the storage modulus of the jute/PLA composite modified by $\mathrm{SiO}_{2}$ is higher than that of the untreated jute/PLA composite. In addition, different variables showed the same change pattern. With the increase of $\mathrm{SiO}_{2}$ content, the storage modulus of the modified jute/PLA composite material increases first and then decreases. The increase in storage modulus and corresponding temperature of chain segment starting to move indicates that the interface adhesion between jute and PLA has been improved, resulting in greater stress transfer between them(Porras and Maranon. 2012). That is, the increase of the $\mathrm{SiO}_{2}$ content can improve the interfacial adhesion, but because of the poor dispersibility of $\mathrm{SiO}_{2}$, when the content is greater than $4 \%$, the effect of the 
331 adhesion begins to decrease.
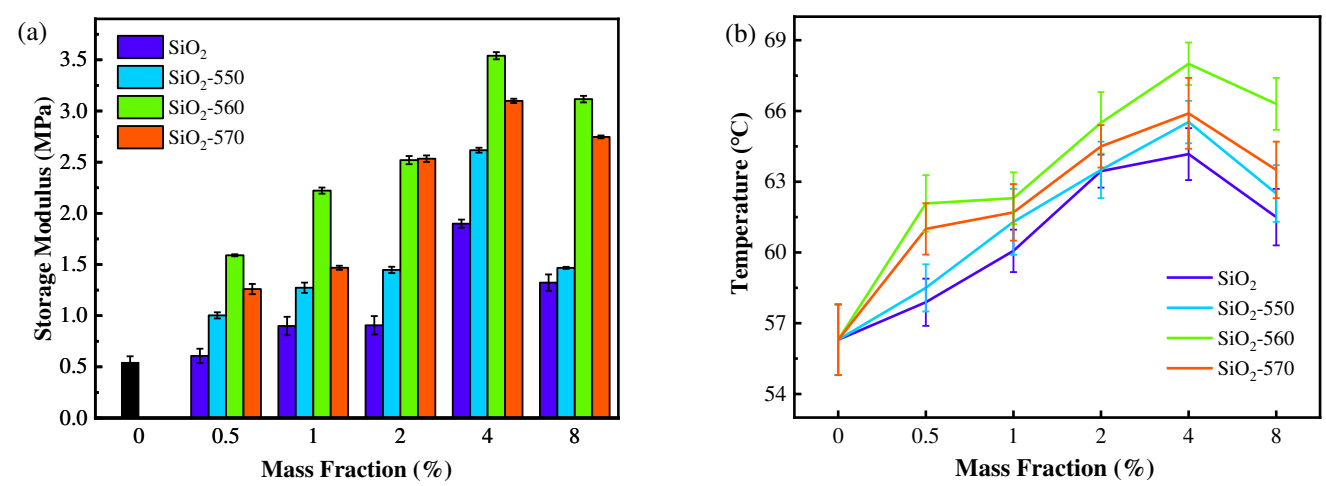

332
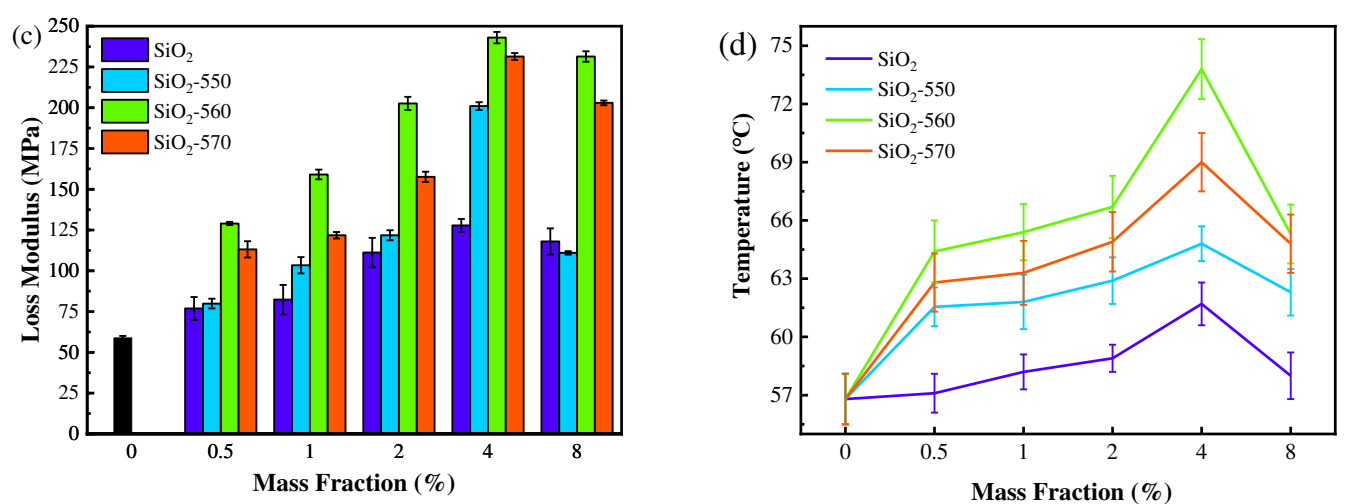

333
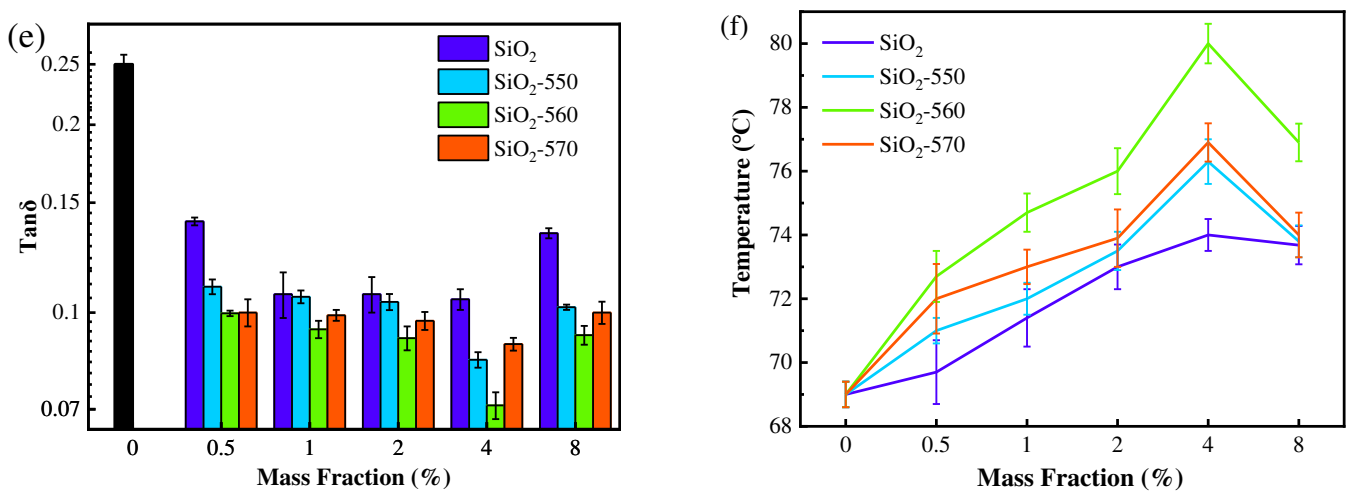


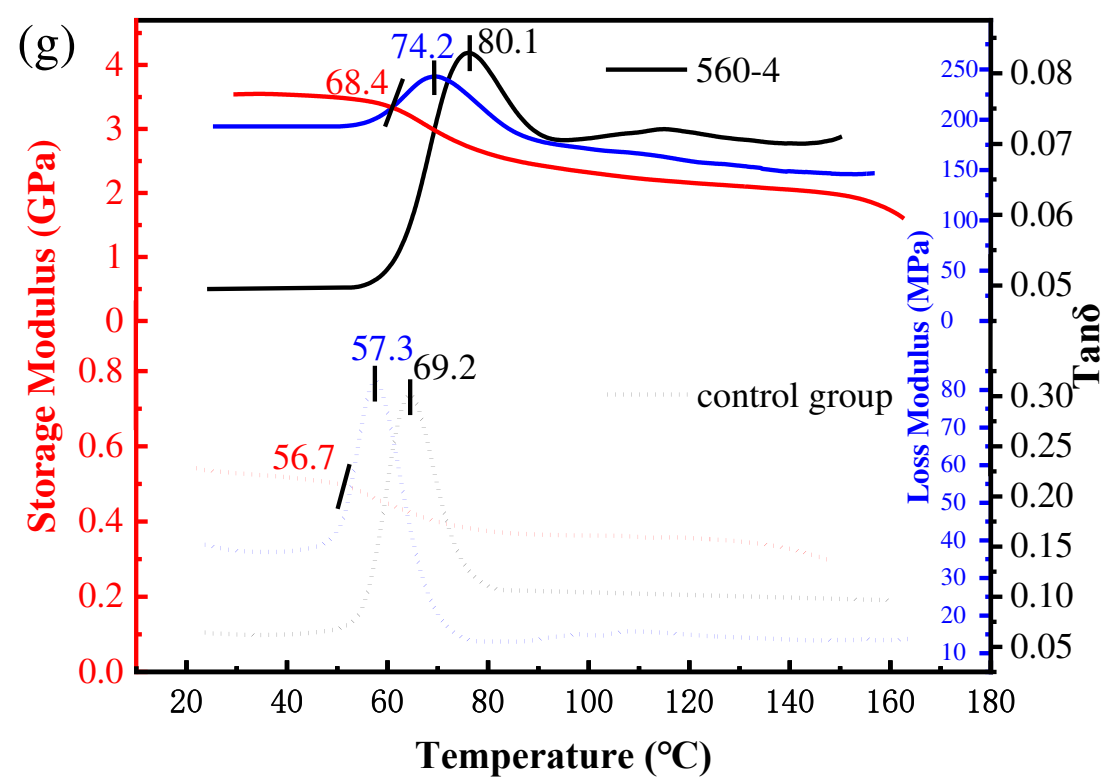

Fig. 11 The DMTA of jute/PLA composite. (a) Storage modulus; (b) The temperature corresponding to storage modulus; (c) The maximum loss modulus; (d) The temperature corresponding to the maximum loss modulus; (e) The maximum tan $\delta$; (f) The temperature corresponding to the maximum $\tan \delta$; (g) The comparison of DMTA between jute/PLA composite and sample 560-4

The next study parameter is the loss modulus, which represents the energy dissipated by the jute/PLA composite under stress (Laly et al. 2003; Doan et al. 2007). It is observed in Figure 11 (c) and (d) that the loss modulus value of the $\mathrm{SiO}_{2}$-modified jute/PLA composite is much higher than that of the untreated jute/PLA composite. It is known that the maximum value of loss modulus corresponds to the glass transition temperature $(\mathrm{Tg})$ of the composite material. The $\mathrm{Tg}$ of the untreated jute/PLA composite is around $57.3{ }^{\circ} \mathrm{C}$. In contrast, the $\mathrm{Tg}$ of the $\mathrm{SiO}_{2}$-modified 349 jute/PLA composite material moved to the high temperature zone, reaching a maximum of about $74.2^{\circ} \mathrm{C}$.

Finally, loss factor, $\tan \delta$, which refers to the ratio of the loss modulus of the composite material to the storage modulus of the composite material, and represents 
the damping energy of the material. The decrease of the tan $\delta$ value indicates $\mathrm{SiO}_{2}$ improves the bonding strength between PLA and jute, and reduces the fluidity of PLA macromolecules in the composite material. Due to the improvement of the hydrophobicity of the $\mathrm{SiO}_{2}$-modified Jute/PLA, the interfacial adhesion is enhanced, and the fluidity of the polymer chains at the jute/PLA composite interface is reduced. Among the unmodified $\mathrm{SiO}_{2}$ and $\mathrm{SiO}_{2}$ jute/PLA composites modified by KH550, KH560 and KH570, the unmodified jute/PLA composites have the highest tan $\delta$ value, and the KH560 modified $\mathrm{SiO}_{2}$ jute/PLA composites has the highest tan $\delta$ value, indicating the dispersibility of $\mathrm{SiO}_{2}$ modified by $\mathrm{KH} 560$ is best. Among all $\mathrm{SiO}_{2}$ composite material modified by KH560, jute/PLA with a $\mathrm{SiO}_{2}$ content of $4 \%$ has the best interface bonding. As shown in Figure 11 (e) and (f).

Comprehensive analysis of sample 560-4 has the best thermomechanical properties. Compared with the jute/PLA composite, the storage modulus, glass transition temperature and loss modulus have increased; $\tan \delta$ has decreased. As shown in Figure $11(\mathrm{~g})$, the comparison of DMTA between jute/PLA composite and sample 560-4. The glass transition temperature of sample 560-4 is $29.5 \%$ higher than that of the jute/PLA composite, indicating that the experimental optimization has improved the bonding strength of the interface between PLA and jute. The storage modulus values of different samples decrease with increasing temperature. The tan $\delta$ value of the jute/PLA composite material increased with the increase of temperature when the mass fraction of $\mathrm{SiO}_{2}$ treated by $\mathrm{KH} 560$ was $4 \%$, until it reached the maximum at $69.2^{\circ} \mathrm{C}$, and then the opposite trend was observed in the rubber area.

\section{Conclusions}

In order to enhance the mechanical properties of the jute/PLA composite, nano- $\mathrm{SiO}_{2}$ particles modified by different coupling agents were introduced into the PLA matrix. The effect of the type of coupling agent and the mass fraction of $\mathrm{SiO}_{2}$ on the bending, stretching and thermomechanical properties of the composite was studied. The study shows that the addition of $\mathrm{SiO}_{2}$ improves the interface performance between PLA and jute and improves the mechanical properties of the composite 
material. Meanwhile, the smaller the particle size of $\mathrm{SiO}_{2}$ and the more uniform the particles, the better the mechanical properties of the composite material. The analysis of thermomechanical properties shows that the addition of $\mathrm{SiO}_{2}$ can improve the thermomechanical properties and glass transition temperature of composite materials. In addition, as shown in the tensile and bending tests, the strength, stiffness and toughness of $\mathrm{SiO}_{2}$ composite material with mass fraction of $4 \%$ modified by the KH560 coupling agent are significantly improved, and its elongation at break is slightly affected. Compared with intact jute/PLA composite, the flexural strength and flexural modulus of sample $560-4$ increase by $150.3 \%$ and $77.4 \%$, respectively, while the tensile strength and tensile modulus increase by $816.9 \%$ and $700.1 \%$, respectively. Its excellent mechanical properties are the result of the better interface compatibility of jute/PLA caused by the $\mathrm{SiO}_{2}-\mathrm{CN}$ bond. In addition, the fracture morphology of the composite material shows that the plastic deformation of the matrix caused by $\mathrm{SiO}_{2}$ are the main toughening mechanisms.

In summary, adding $\mathrm{SiO}_{2}$ modified by coupling agent to jute/PLA composites can improve the mechanical properties of composites, which can be used in packaging, automotive and other industries. Make products more green and environmentally friendly.

\section{Acknowledgements}

The work is gratefully supported by National Natural Science Foundation of China (Grant No.11602156), Science and Technology Guiding Project of China National Textile and Apparel Council (Grant No. 2020064).

\section{Declaration of competing interest}

The authors declare that they have no known competing financial interests or personal relationships that could have appeared to influence the work reported in this paper.

\section{References}

Bax B, Mussig J (2008) Impact and tensile properties of PLA/cordenka and PLA/flax 
composites. Composites Science and Technology 68(7-8):1601-1607. https://doi.org/10.1016/j.compscitech.2008.01.004

Balla VK, Kate KH, Satyavolu J, et al (2019) Additive manufacturing of natural fiber reinforced polymer composites: Processing and prospects. Composites Part-B Engineering 174:106956. https://doi.org/10.1016/j.compositesb.2019.106956

Costa S, Ferreira D, Ferreira A, et al (2012) Multifunctional flax fibres based on the combined effect of silver and zinc oxide $(\mathrm{Ag} / \mathrm{ZnO})$ nanostructures. Nanomaterials 8(12):1069. https://doi.org/10.3390/nano8121069

Cheon J, Kim M (2021) Impact resistance and interlaminar shear strength enhancement of carbon fiber reinforced thermoplastic composites by introducing MWCNT-anchored carbon fiber. Composites Part B: Engineering 217:108872. https://doi.org/10.1016/j.compositesb.2021.108872

Doan TTL, Brodowsky H, Mader E (2007) Jute fibre/polypropylene composites II. Thermal, hydrothermal and dynamic mechanical behaviour. Composites Science and Technology 67(13):2707-2714. https://doi.org/10.1016/j.compscitech.2007.02.011

Dong Y, Ghataura A, Takagi H, et al (2014) PLA biocomposites reinforced with coir fibres: evaluation of mechanical performance and multifunctional properties. Composites Part A: Applied Science and Manufacturing 63(18):76-84. https://doi.org/10.1016/j.compositesa.2014.04.003

Dong Y, Ghataura A, Takagi H, et al (2014) PLA biocomposites reinforced with coir fibres: evaluation of mechanical performance and multifunctional properties. Composites Part A: Applied Science and Manufacturing 63(18): 76-84. https://doi.org/10.1016/j.compositesa.2014.04.003

Dong AX, Wu HM, Liu RR, et al (2020) Horseradish peroxidase-mediated functional hydrophobization of jute fabrics to enhance mechanical properties of jute/thermoplastic composites PLA biocomposites reinforced with coir. Polymer Engineering and Science 2020: 25612. https://doi.org/10.1002/pen.25612

Faruk O, Bledzki AK, Fink HP, et al (2012) Biocomposites reinforced with natural fibers: 2000-2010. Progress in Polymer Science 37(11):1552-1596. 
https://doi.org/10.1016/j.progpolymsci.2012.04.003

Fang CC, Zhang Y, Qi SY, et al (2020) Characterization and analyses of degradable composites made with needle-punched jute nonwoven and polylactic acid (PLA) membrane.

Cellulose 27(10):5971-5980. https://doi.org/10.1007/s10570-020-03204-8

Fang CC, Zhang Y, Qi SY, et al (2020) Influence of structural design on mechanical and thermal properties of jute reinforced polylactic acid (PLA) laminated composites.

Cellulose 27(16):9397-9407. https://doi.org/10.1007/s10570-020-03436-8

Gauvin F, Cousin P, Robert M (2015) Improvement of the interphase between basalt fibers and vinylester by nano-reinforced post-sizing. Fibers and Polymer 16(2):434-442. https://doi.org/10.1007/s12221-015-0434-X

Huda MS, Drzal LT, Mohanty AK, et al (2007) Effect of fibers surface-treatments on the properties of laminated biocomposites from poly (lactic acid) (PLA) and kenaf fibers. Composites Science and Technology 68(2):424-432. https://doi.org/10.1016/j.compscitech.2007.06.022

He H, Tay TE, Wang Z, et al (2019) The strengthening of woven jute fibers/polylactide biocomposite without loss of ductility using rigid core-soft shell nanoparticles. Journal of Materials Science 54(6):4984-4996. https://doi.org/10.1007/s10853-018-03206-9

Hashim UR, Jumahat A, Mahmud J (2019) Improved tensile properties of basalt fibre reinforced polymer composites using silica nanoparticles. Materialwissenschaft und Werkstofftechnik 50(9):1149-1155. https://doi.org/10.1002/mawe.201800071

Hossen M, Feng J, Yuxiang Y, et al (2020) Preparation and evaluation mechanical, chemical and thermal properties of hybrid jute and coir fibers reinforced bio-composites using poly-lactic acid and poly-caprolactone blends. Materials Research Express 7(2):025103. https://doi.org/10.1088/2053- 1591/ab952b

Kumar R, Yakabu MK, Anandjiwala RD (2010) Effect of montmorillonite clay on flax fabric reinforced poly lactic acid composites with amphiphilic additives. 
Composites Part A-Applied Science and Manufacturing 41(11):1620-1627. https://doi.org/10.1016/j.compositesa.2010.07.012

Kakroodi AR, Bainier J, Rodrigue D (2012) Mechanical and morphological properties of flax fibers reinforced high density polyethylene/recycled rubber composites. International Polymer Processing 27(2):196-204. https://doi.org/10.3139/217.2473

Laly AP, Zachariach O, Sabu T (2003) Dynamic mechanical analysis of banana fibers reinforced polyester composites. Composites Science and Technology 63(2):283-293. https://doi.org/10.1016/S0266-3538(02)00254-3

Li X, Lei B, Lin Z, et al (2013) The utilization of bamboo charcoal enhances wood plastic composites with excellent mechanical and thermal properties. Materials and Design 53(1):419-424. https://doi.org/10.1016/j.matdes.2013.07.028

Luo H, Ding J, Huang Z, et al (2018) Investigation of properties of nano-silica modified epoxy resin films and composites using RFI technology. Composites Part B 155:288-298. https://doi.org/10.1016/j.compositesb.2018.08.055

Jumahat A, Soutis C, Jones FR, et al (2010) Effect of silica nanoparticles on compressive properties of an epoxy polymer. Journal of Materials Science 45(21):5973-5983. https://doi.org/10.1007/s10853-010-4683-1

Jumahat A, Soutis C, Mahmud J, et al (2012) Compressive properties of nanoclay/epoxy nanocomposites. Procedia Engineering 41:1607-1613. https://doi.org/10.1016/j.proeng.2012.07.357

Jumahat A, Soutis C, Abdullah SA, et al (2012) Tensile properties of nanosilica/eepoxy nanocomposites. Procedia Engineering 41:1634-1640. https://doi.org/10.1016/j.proeng.2012.07.361

Jumahat A, Kasolang S, Ba Hari MT (2015) Wear properties of nanosilica filled epoxy polymers and FRP composites. Jurnal Tribologi 6:24-36.

Mohammed L, Ansari MNM, Pua G, et al (2019) A review on natural fibers reinforced polymer composite and its applications. International Journal of Polymer Science 2015:243947. https://doi.org/10.1155/2015/243947

Nishino T, Hirao K, Kotera M, et al (2003) Kenaf reinforced biodegradable composite. 


$$
\text { Composites Science and Technology 63(9):1281-1286. }
$$
https://doi.org/10.1016/s0266-3538(03)00099-x

Pan PJ, Zhu B, Kai W, et al (2007) Crystallization behavior and mechanical properties of bio-based green composites based on poly(L-lactide) and kenaf fibers. Journal of Applied Polymer Science 105(3):1511-1520. https://doi.org/10.1002/app.26407

Porras A, Maranon A (2012) Development and characterization of a laminate composite material from polylactic acid (PLA) and woven bamboo fabric.

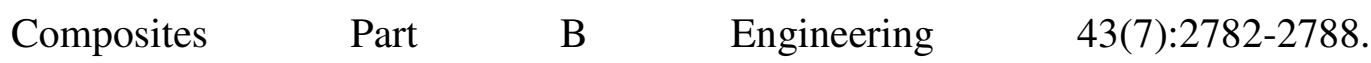
https://doi.org/10.1016/j.compositesb.2012.04.039

Pereira JF, Ferreira DP, Pinho E, et al (2019) Chemical and biological warfare protection and self-decontaminating flax fabrics based on $\mathrm{CaO}$ nanoparticles. $\begin{array}{llll}\text { Key Engineering } & \text { Materials }\end{array}$ https://doi.org/10.4028/www.scientific.net/kem.812.75

Park JE, Seok BY (2020) Mechanical properties of inorganic particle reinforced epoxy composites for gas insulated switchgear. Journal of Mechanical Science and Technology 34(7):2795-2799. https://doi.org/10.1007/s12206-020-0612-7

Qu P, Gao Y, Wu GF, et al (2015) Nanocmposites of poly (lactic acid) reinforced with cellulose nanofibrils. Bioresources 5(3):1811-1823.

Reddy CS, Das CK, Narkis M (2010) Propylene-ethylene copolymer nanocomposites: epoxy resin grafted nanosilica as a reinforcing filler. Polym Compos 26(6):806-12. https://doi.org/10.1002/pc.20145

Sanivada UK, Gonzalo M, Brito FP, et al (2020) PLA composites reinforced with flax and jute fibers-A review of recent trends, processing parameters and mechanical properties. Polymers 12(10):2373. https://doi.org/10.3390/polym12102373

Wang D, Xuan L, Han G, et al (2020) Preparation and characterization of foamed wheat straw fiber/polypropylene composites based on modified nano-TiO2 particles. Composites Part A Applied Science and Manufacturing 128:105674. https://doi.org/10.1016/j.compositesa.2019.105674

Yang HF, Li FH, Shan CS, et al (2009) Covalent functionalization of chemically 
Figures

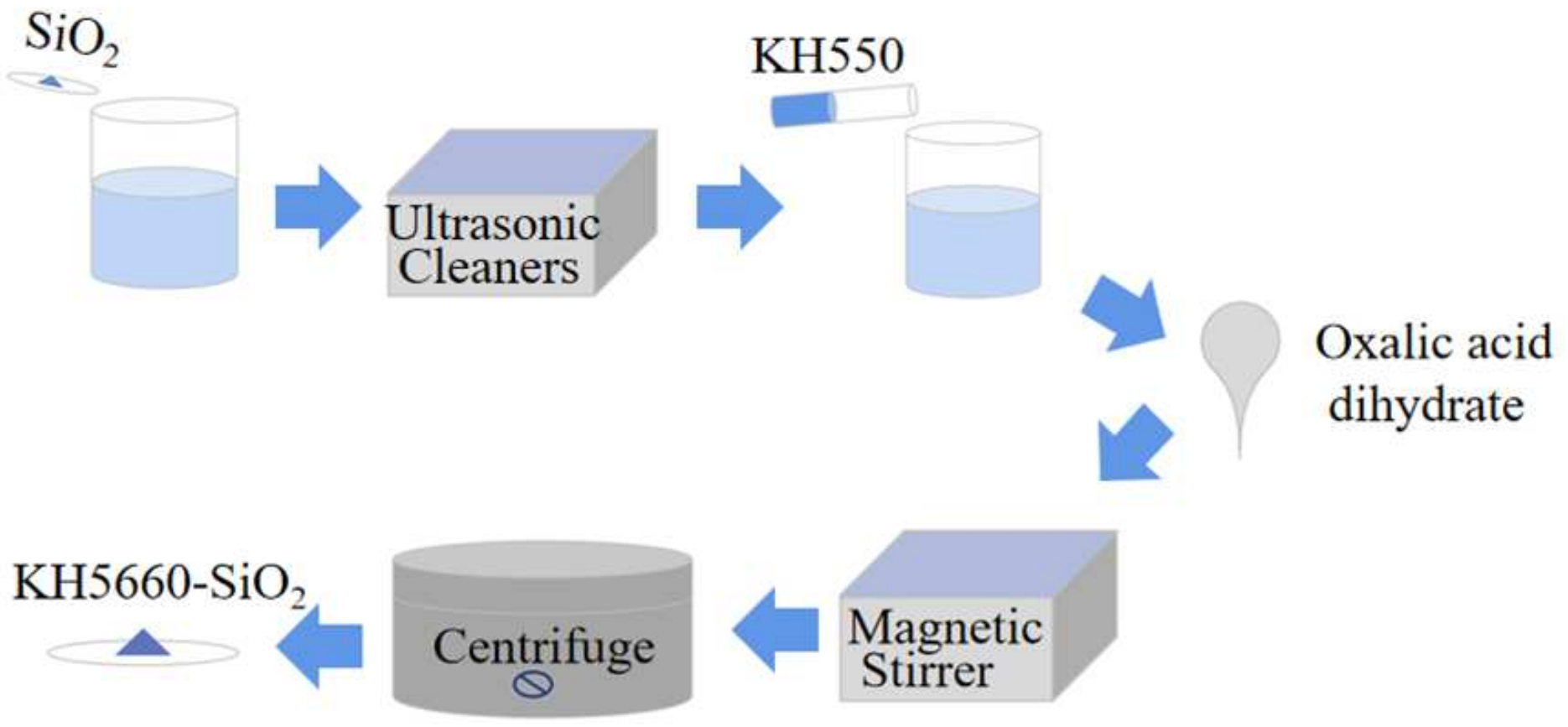

Figure 1

The scheme of preparation process of modified SiO2

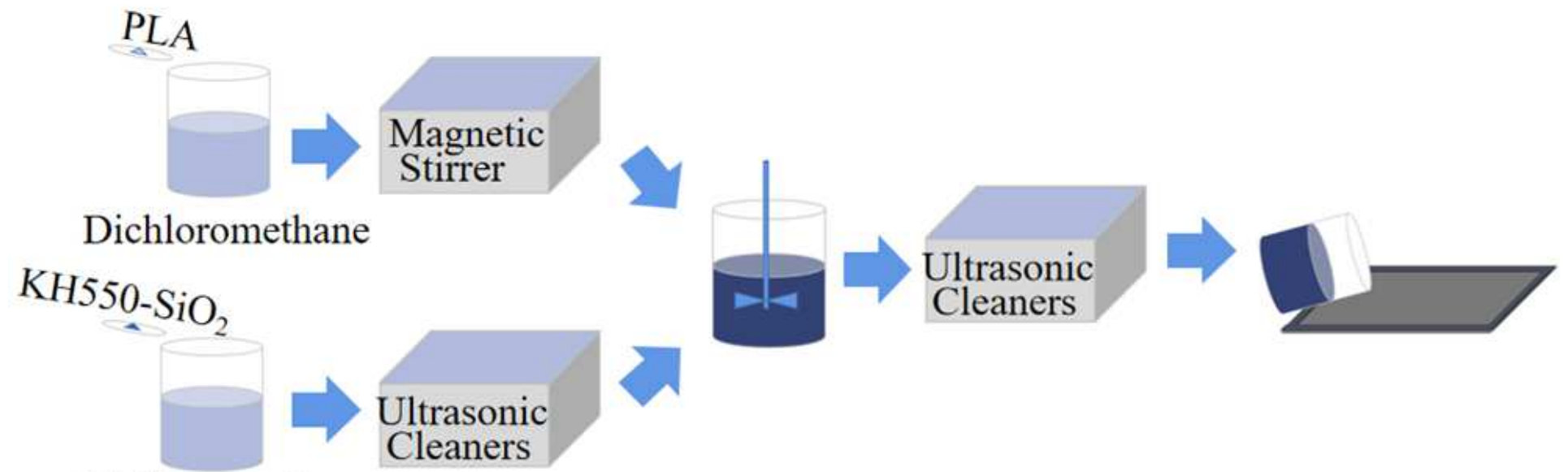

Dichloromethane

Figure 2

The scheme of preparation process of composite SiO2-PLA film 


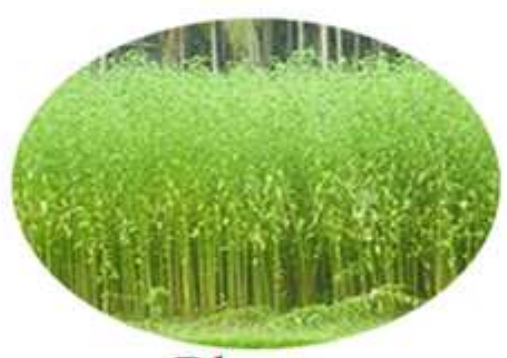

Plant

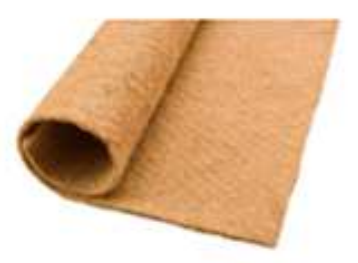

Jute nonwovens

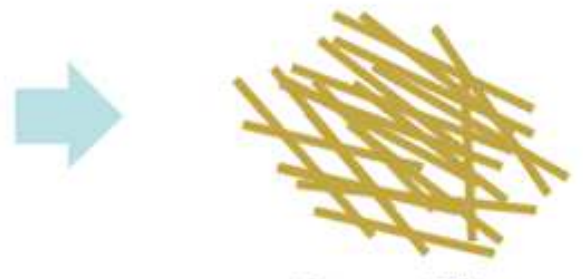

Jute fiber

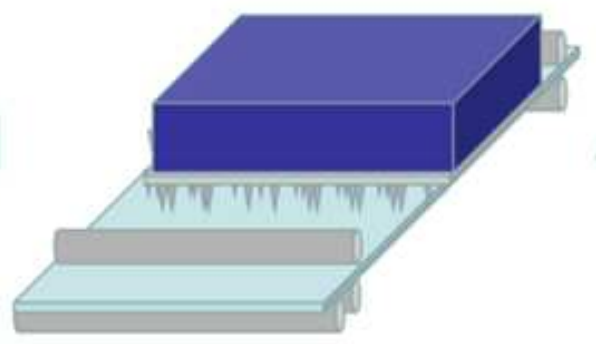

Pre-needling

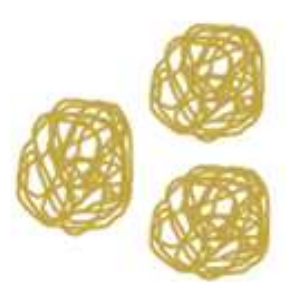

Blending

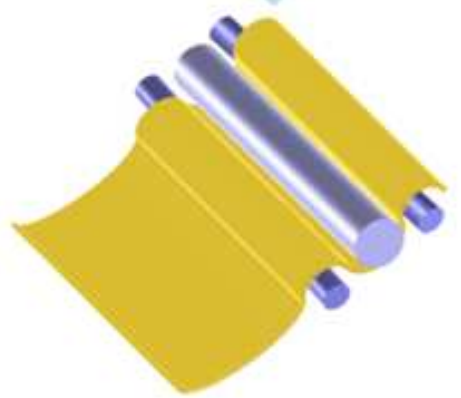

Cross lapping

Figure 3

The preparation process of jute non-woven fabric
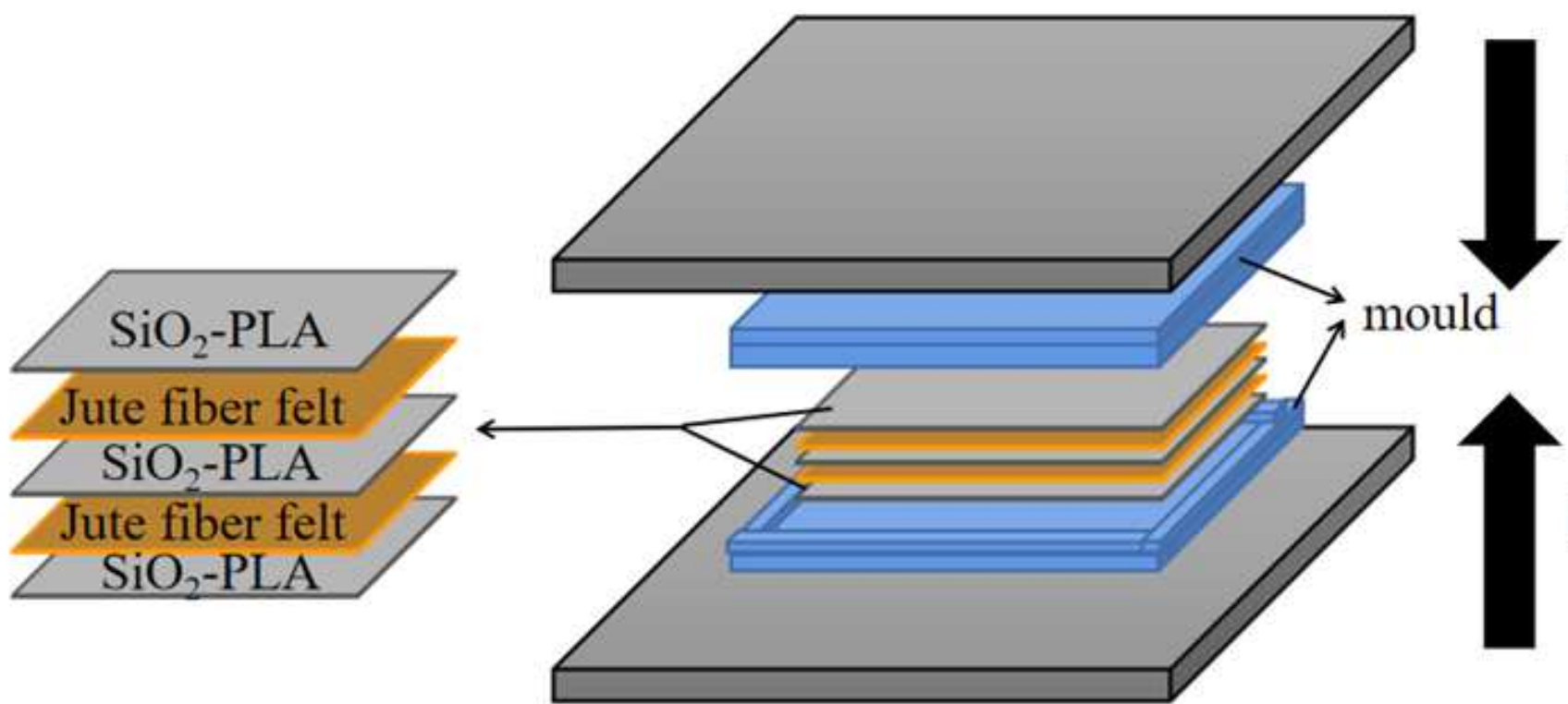

Heat

Press

\section{Figure 4}

The preparation process of composite material 

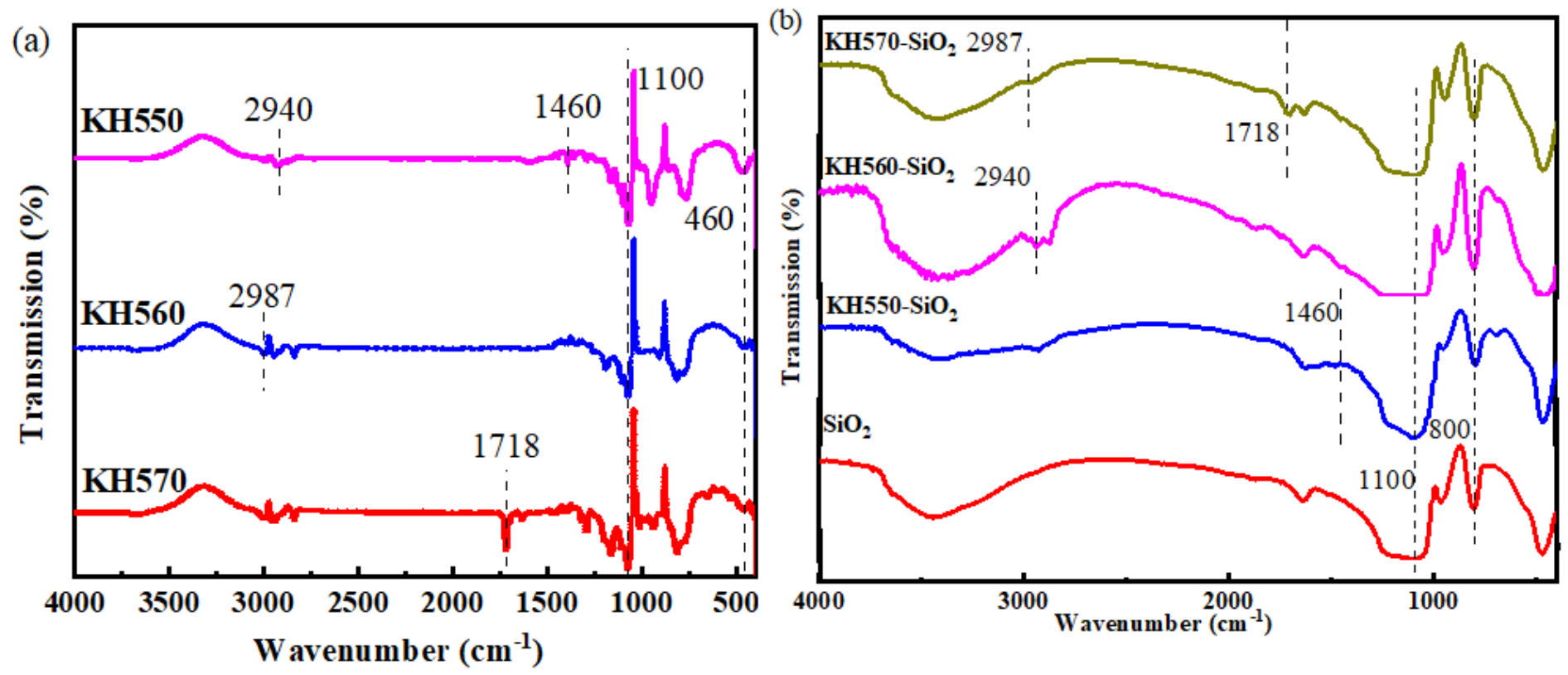

Figure 5

(a) FTIR spectra of KH550, KH560 and KH570; (b) FTIR spectra of SiO2, KH550-SiO2, KH560-SiO2 and KH570-SiO2 nanoparticle

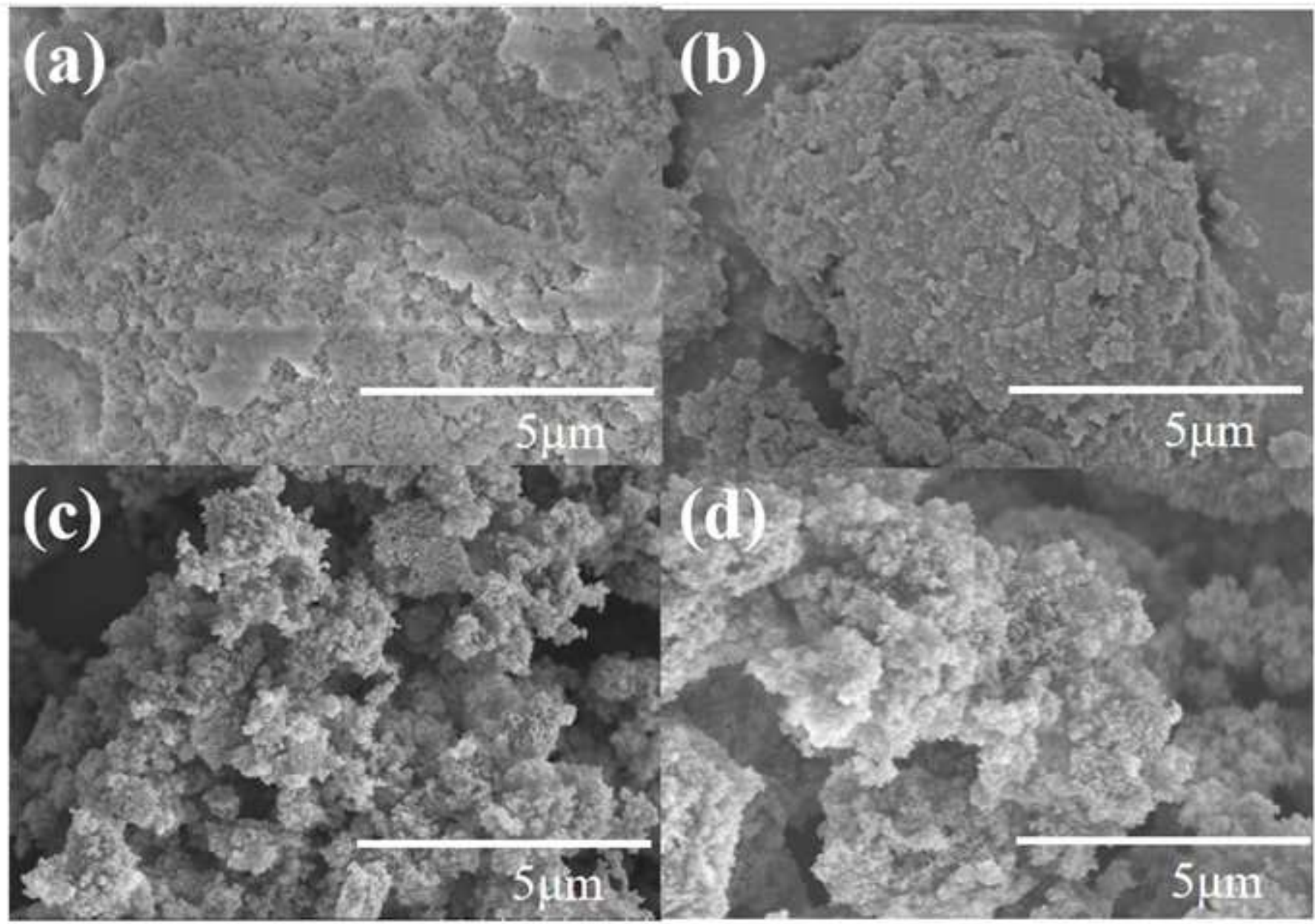


Figure 6

The surface morphology of SiO2. (a) SiO2; (b) SiO2-550; (c) SiO2-560; (d) SiO2-570
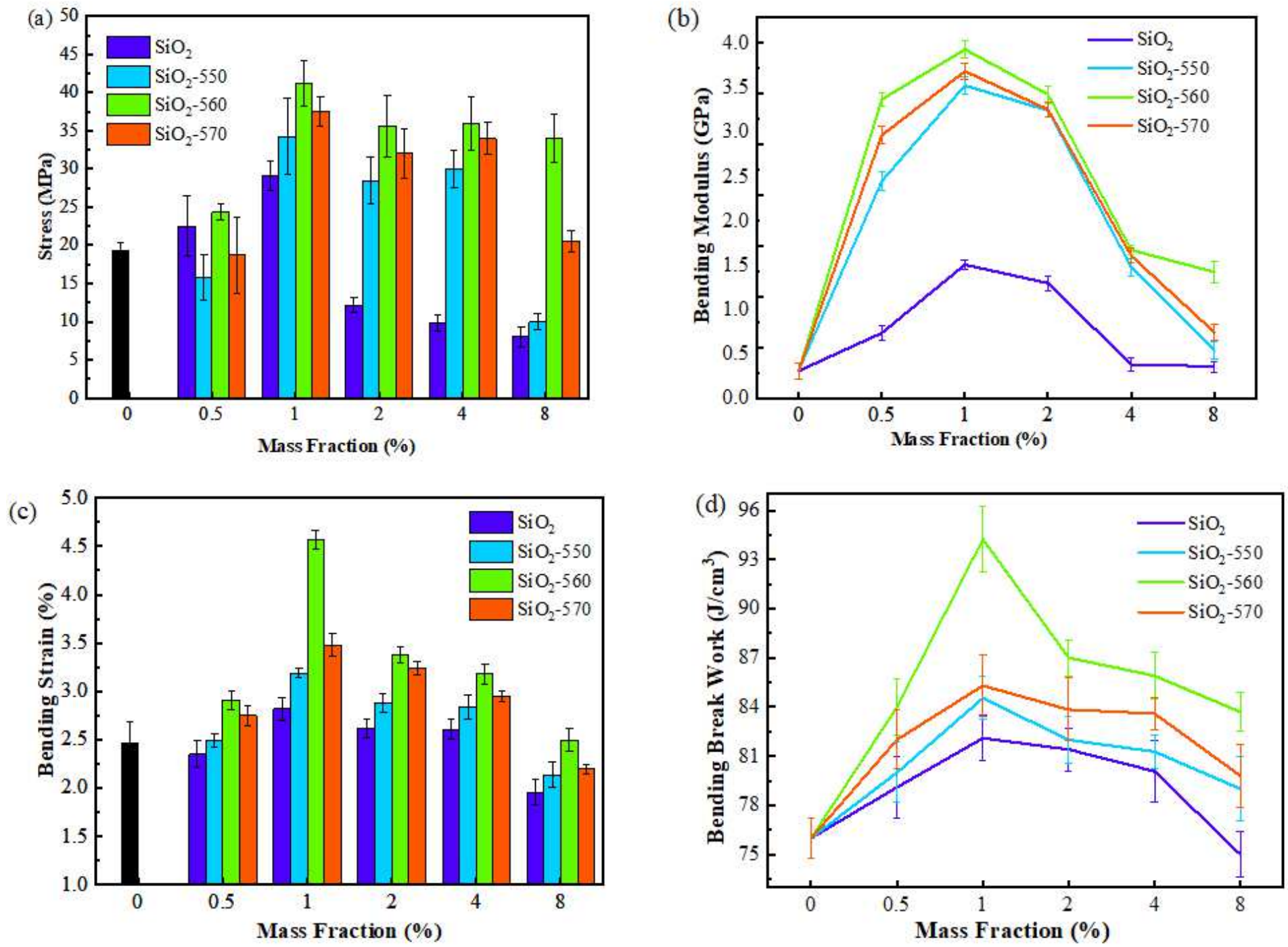

Figure 7

The effect of nano-SiO2 on tensile properties of jute/PLA composite bending performance. (a) Bending strength; (b) Modulus; (c) Bending strain; (d) Bending break work 

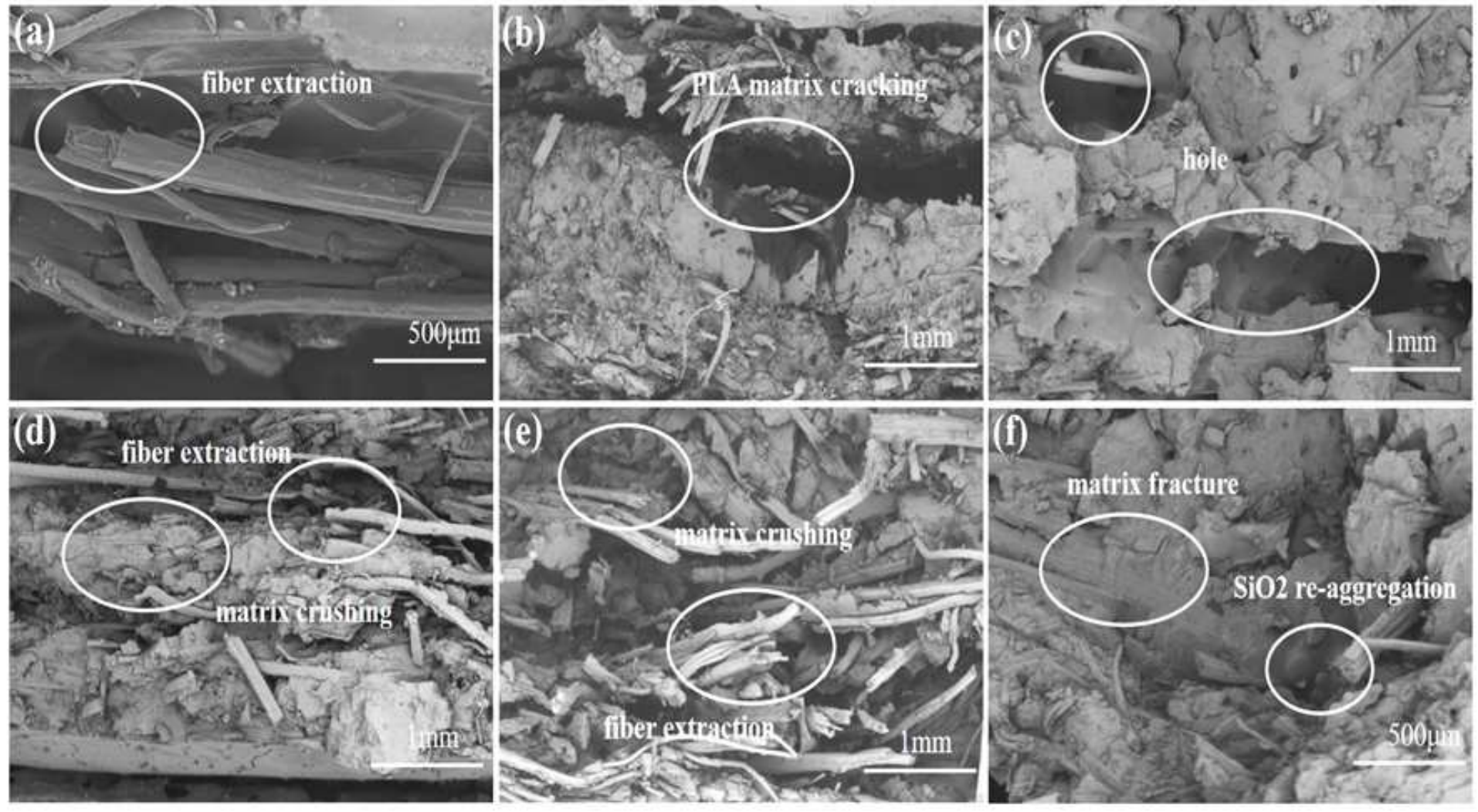

\section{Figure 8}

The fracture surface morphologies of jute/PLA composite $(\times 200)$. (a) jute/PLA composite. (b) Sample 560-0.5. (c) Sample 560-1. (d) Sample 560-2. (e)Sample 560-4. (f) Sample 560-8 

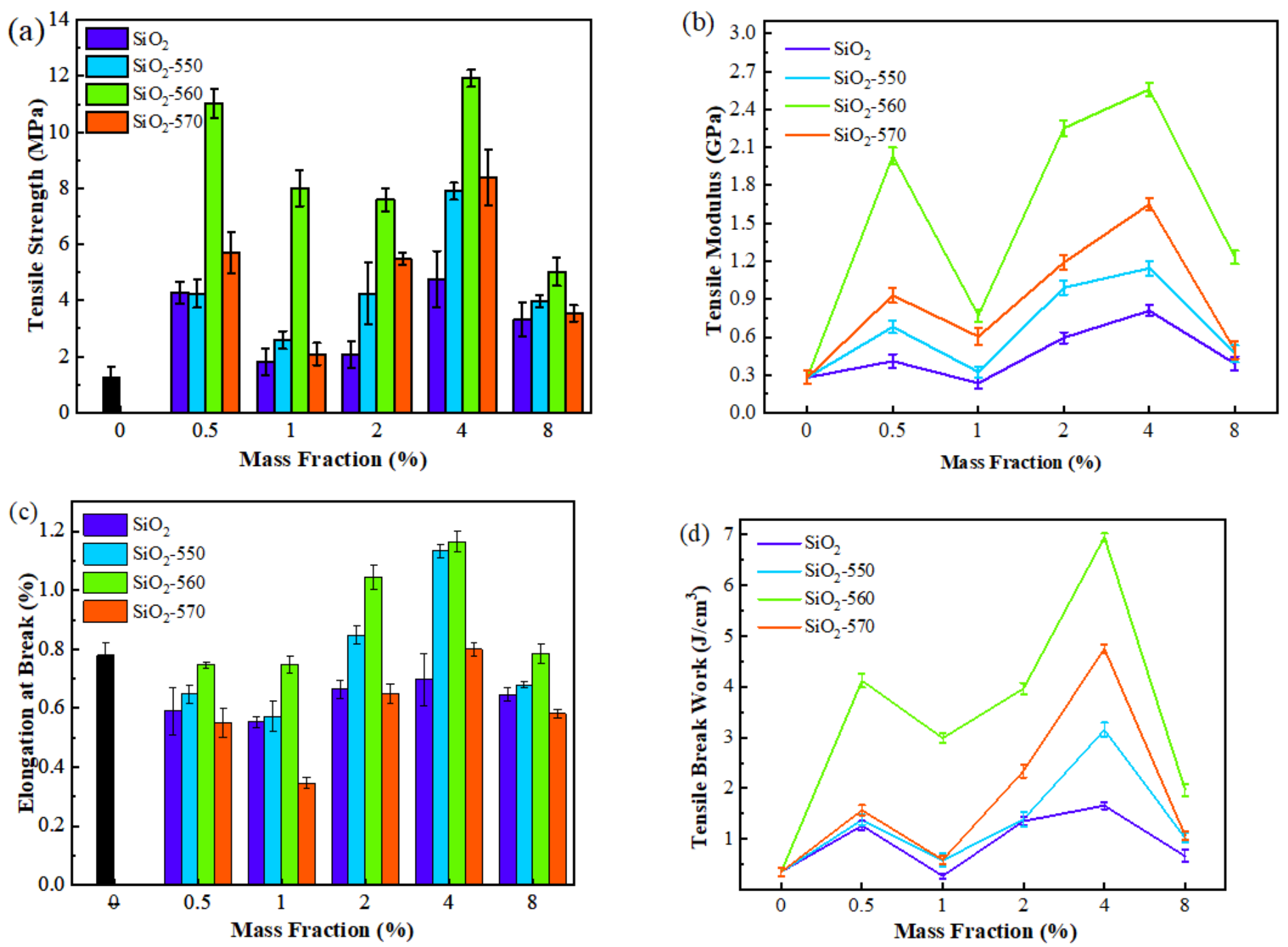

Figure 9

The effect of nano-SiO2 on tensile properties of jute/PLA fibers composites. (a) Tensile strength; (b)modulus; (c) Elongation at break; (d) Tensile break work 
Binding site $\mathrm{SiO}_{2}$
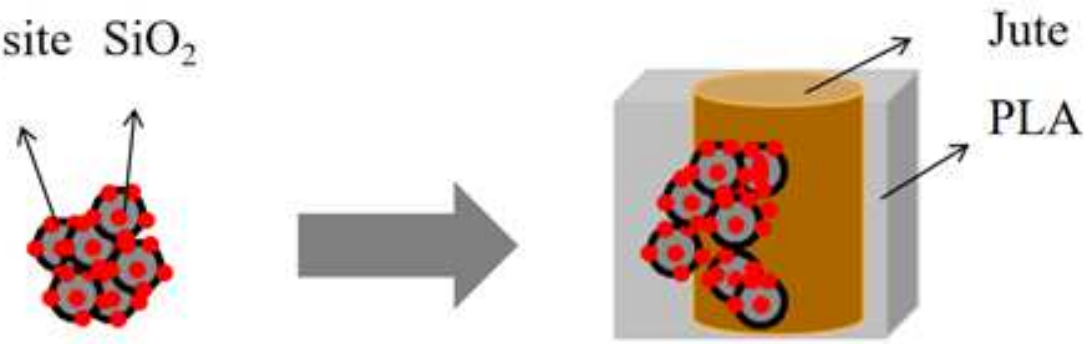

Silica agglomeration

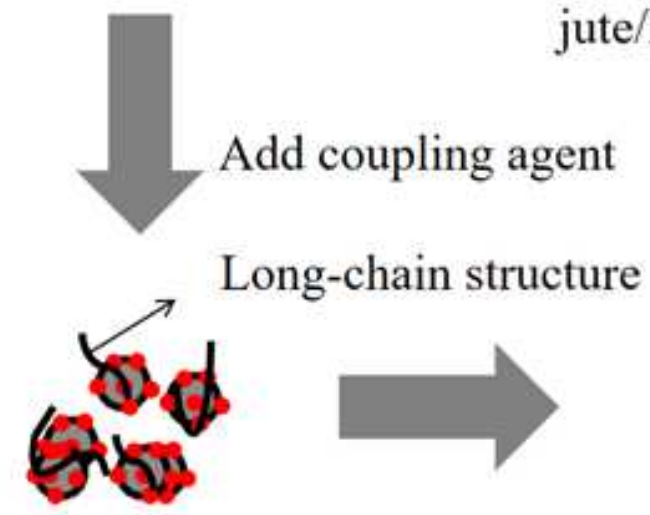

After addition of the unmodified $\mathrm{SiO}_{2}$, jute/PLA interaction interface

Silane coupling agent reacts with hydroxyl groups on the surface of $\mathrm{SiO}_{2}$

\section{Figure 10}

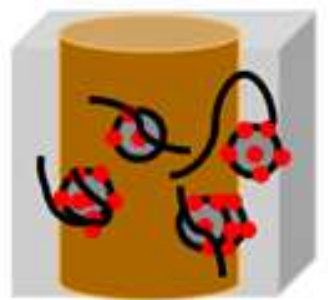

After addition of the modified-SiO ${ }_{2}$, jute/PLA interaction interface

The interaction between the silica particles and the interface of the jute/PLA composite before and after the modification of the silane coupling agent. 

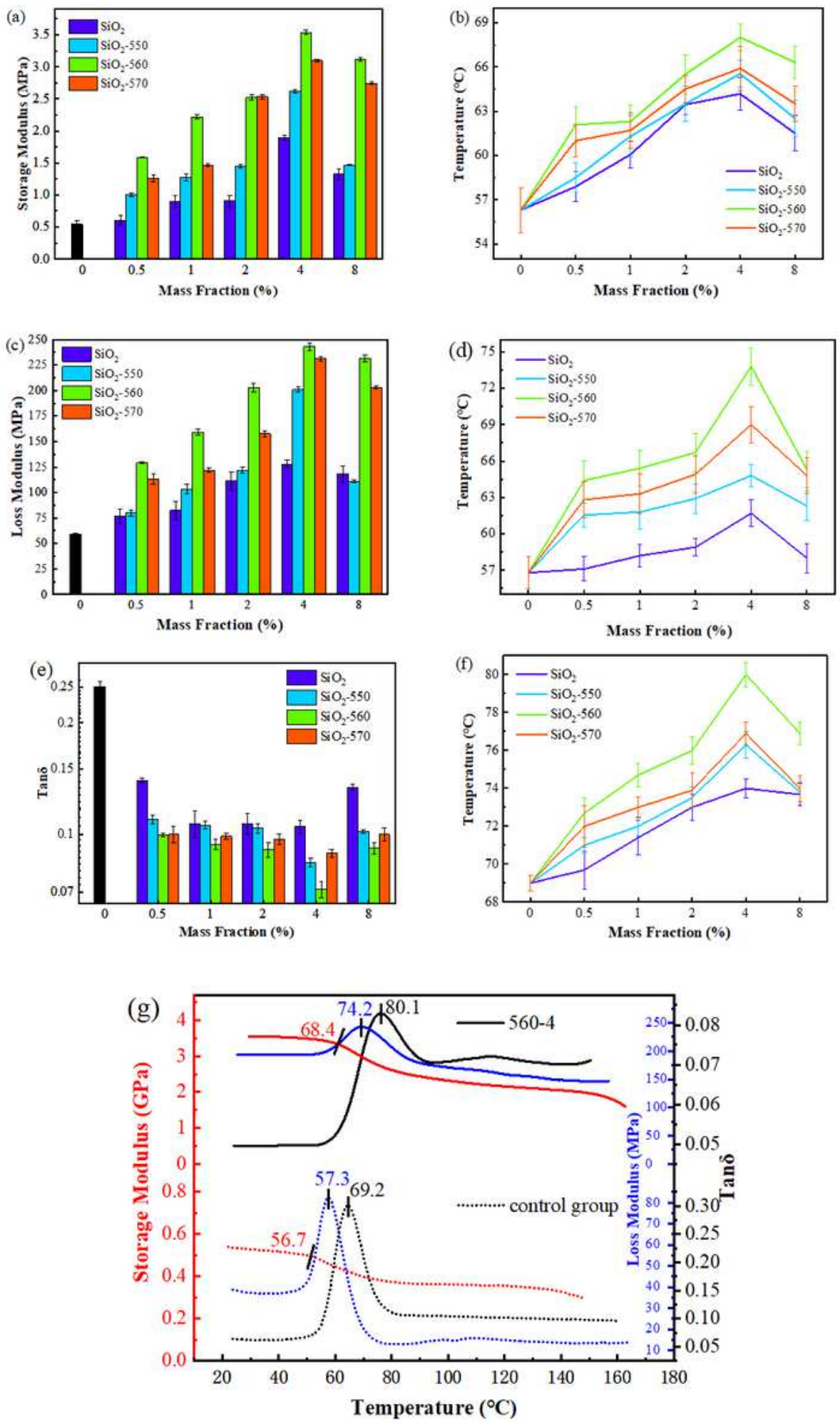

Figure 11

The DMTA of jute/PLA composite. (a) Storage modulus; (b) The temperature corresponding to storage modulus; (c) The maximum loss modulus; (d) The temperature corresponding to the maximum loss modulus; (e) The maximum tan $\delta$; $(\mathrm{f})$ The temperature corresponding to the maximum tan $\delta$; $(\mathrm{g})$ The comparison of DMTA between jute/PLA composite and sample 560-4 


\section{Supplementary Files}

This is a list of supplementary files associated with this preprint. Click to download.

- renamed90625.doc 